\title{
Evaluation of the stochastic weather generators LARS-WG and AAFC-WG for climate change impact studies
}

\author{
Budong Qian*, Henry Hayhoe, Sam Gameda \\ Eastern Cereal and Oilseed Research Centre, Agriculture and Agri-Food Canada, 960 Carling Avenue, \\ Ottawa K1A 0C6, Canada
}

\begin{abstract}
There is a need to know how well stochastic weather generators can produce daily climate scenarios for climate change impact studies. In this study, 2 stochastic weather generators (LARS-WG and AAFC-WG) were assessed, based on an experiment with historical daily climate data. The experiment was conducted for 3 stations in Canada, using 1911-1940 as the baseline climate period and 1971-2000 as the changed climate period. Weather generators were calibrated with the baseline data. Daily climate scenarios were then generated for 1971-2000, using parameters that were adjusted to reflect climate change. Different schemes for modifying weather generator parameters were assessed in relation to their capability to reproduce statistical properties of daily climate data for a changed climate. Using changes in the statistics of daily climate data between the baseline climate and the changed climate period, it became feasible to modify parameters for the weather generators that use empirical distributions. For reproducing changes in frequency of wet and dry spells, modification schemes with a full adjustment (all 2nd order transition probabilities being modified separately) for the 2nd order Markov chain appeared more effective than the modification to mean length of wet and dry spells. Separate adjustments for maximum (Tx) and minimum (Tn) temperature, rather than modification on the basis of changes in daily mean temperature, might also be necessary. The probability distribution of daily precipitation amount $(\mathrm{P})$ in a changed climate seemed more difficult to simulate well, although the means and variances were produced better. In general, daily climate scenarios developed by weather generators can be reasonably reliable for agricultural impact studies, provided the changes in the statistics of daily weather variables from daily GCM output are reliable. Otherwise, downscaling may be required to obtain reliable changes in the statistics of local daily weather variables.
\end{abstract}

KEY WORDS: Stochastic weather generator - Climate change - Climate scenarios - Impact study Resale or republication not permitted without written consent of the publisher

\section{INTRODUCTION}

Stochastic weather generators have attracted attention in the past decade as a convenient tool for producing daily scenarios in climate change impact studies. This technique is often based on modifying, or perturbing, weather generator parameters with statistics from climate change scenarios generated by GCM (general circulation models, or global climate models) at monthly or daily timescales (Wilks 1992, Katz 1996, Mearns et al. 1997, Semenov \& Barrow 1997). The resulting daily climate scenarios can be used as input for impact models, such as crop yield models, to assess cli- mate change impacts. Weather generator parameters represent the climate for the period used to calibrate the weather generator. For example, a weather generator calibrated from weather data observed during 1971-2000 can be used to generate synthetic weather data for an arbitrarily long period, but the generated synthetic weather data will only be a series of realizations of the climate observed in 1971-2000. Daily climate scenarios generated by stochastic weather generators with perturbed parameters can be a realization for a changed climate. There is a need to determine how well weather generators can simulate a changed climate; this can be done by testing the effects of modi- 
fications to the input parameters. Research is also required to determine how to best use available climate change information from GCM simulations to adjust (or perturb) weather generator parameters.

A stochastic weather generator is usually validated by comparing statistics computed from a synthetic weather series generated by the weather generator against those from observed weather data. This approach is also used to compare different types of weather generators (Semenov et al. 1998, Qian et al. 2004a). Future climate scenarios are often compared on the basis of the procedure by which the scenarios are developed. For example, climate scenarios generated from regional climate model experiments have been compared with those from statistical downscaling (Mearns et al. 1999) to show uncertainties introduced by downscaling techniques. To our knowledge there has not been any assessment on the capability of weather generators to accurately reproduce the statistical properties of future climate scenarios.

Statistics of daily weather series are related to the monthly statistics (Wilks 1992, Katz 1996, Mearns et al. 1997), and adjusting weather generator parameters using monthly statistics is easy and reliable for stochastic models with simple probability distributions. However, relationships between monthly and daily values may not be applicable to the weather generators that use empirical distributions, such as LARS-WG (Semenov et al. 1998) and AAFC-WG (Hayhoe 2000, Qian et al. 2004a). Therefore, finding appropriate approaches to modifying parameters for weather generators employing empirical distributions needs more attention. As GCM output becomes widely available on daily time scales, it is possible to use climate change scenarios derived from daily GCM output instead of monthly output.

This study used historical weather data to assess the capability of weather generators for simulating the statistical properties of daily climate scenarios for a changed climate. We also analyzed how this capability was associated with the methods employed to modify weather generator parameters.

\section{DATA AND METHODOLOGY}

\subsection{Daily climate data}

Two different periods of historical weather observations were employed to assess the abilities of weather generators in simulating selected statistics of a weather series for a changed climate. Weather data at 3 Canadian stations, Ottawa $\left(45^{\circ} 23^{\prime} \mathrm{N}, 75^{\circ} 43^{\prime} \mathrm{W}\right)$, Toronto $\left(43^{\circ} 40^{\prime} \mathrm{N}, 79^{\circ} 24^{\prime} \mathrm{W}\right)$ and Regina $\left(50^{\circ} 26^{\prime} \mathrm{N}\right.$, $104^{\circ} 40^{\prime} \mathrm{W}$ ), for the period 1911-1940 were used to calibrate the weather generators LARS-WG and AAFC-WG. Weather data for 1971-2000 were used to evaluate the performance of the weather generators in simulating a changed climate. The latter decades have been reported to exhibit climate change due to the enhanced effect of greenhouse gases (Folland et al. 2001, Jones et al. 2001). Daily precipitation (P), and maximum (Tx) and minimum (Tn) temperature were extracted from historical weather data sets archived at Agriculture and Agri-Food Canada for the 3 stations. Changes in statistics of daily $\mathrm{P}, \mathrm{Tx}$ and Tn between the two 30 yr periods were determined (see Section 3). In addition, 9 agroclimatic indices, mainly relevant to temperature conditions for crop growing, were also analyzed to see whether differences were significant between the 2 periods. Details about these agroclimatic indices were given in Qian et al. (2004a).

\subsection{Review of parameter adjustments based on statistics of monthly values}

Conventionally, weather generators have been used in climate change studies to develop daily climate scenarios based on monthly statistics, such as the means and the variances of monthly $\mathrm{P}$ totals, and of monthly mean temperature (Wilks 1992, Mearns et al. 1997, Semenov \& Barrow 1997). Adjusting weather generator parameters is the key technique in this approach. As climate change scenarios from archived GCM outputs were available mainly on a monthly time scale about a decade ago, parameter adjustment was based on the relationship of statistics between monthly and daily values and some additional scenario-specific constraints which depend on other available information or the objectives of a particular climate impact study and may be varied as part of sensitivity analyses (Wilks 1992). These relationships were usually established for simple stochastic models, such as a daily precipitation model with a 2-state firstorder Markov chain for simulating P occurrence and a gamma distribution for generating P (e.g. Wilks 1992, Mearns et al. 1997).

For the above precipitation model, occurrence of $\mathrm{P}$ depends only on the transition probability of a wet day following a dry day $\left(p_{01}\right)$ and the probability of a wet day following a wet day $\left(p_{11}\right)$. These 2 transition probabilities can be described by 2 other parameters: the probability of a wet day, $\pi$, and the dependence parameter, $d$, which indicates the strength of the persistence (Katz 1983, 1985):

$$
\pi=\frac{p_{01}}{1+p_{01}-p_{11}} \text { and } d=p_{11}-p_{01}
$$


The probability density function for the gamma distribution, which is used to characterize the variation of amounts of $\mathrm{P}$, is given by:

$$
f(x)=\frac{(x / \beta)^{\alpha-1} \exp (-x / \beta)}{\beta \Gamma(\alpha)} ; x, \alpha, \beta>0 ;
$$

where the distribution parameters are $\alpha$ (the shape parameter) and $\beta$ (the scale parameter), $x$ is the daily amount of $\mathrm{P}$, and $\Gamma(\cdot)$ denotes the gamma function. The mean amount of $\mathrm{P}, \mu$, and the corresponding variance $\sigma^{2}$ are related to the shape parameter and the scale parameter as $\mu=\alpha \beta$, and $\sigma^{2}=\alpha \beta^{2}$. Therefore, this stochastic daily precipitation model is completely described by the 4 parameters $\pi, d, \alpha$ and $\beta$.

According to Katz $(1983,1985)$, the average monthly total of $\mathrm{P}, \mu_{m}$, and its variance, $\sigma_{\mathrm{m}}^{2}$ comprised of $N$ days have the following relationships to the 4 parameters in this precipitation model

$$
\begin{gathered}
\mu_{m}=N \pi \alpha \beta, \\
\text { and for large } N, \quad \sigma_{m}^{2} \approx N \pi \alpha \beta^{2}\left[1+\alpha(1-\pi) \frac{1+d}{1-d}\right]
\end{gathered}
$$

Considering the ratios of the above quantities in a changed climate to those characterizing the baseline climate, e.g. for 1961-1990, and denoting those symbols pertaining to the changed climate (e.g. 2040-2069) with a superscript prime, yields:

$$
\frac{\mu_{m}^{\prime}}{\mu_{m}}=\frac{\pi^{\prime} \alpha^{\prime} \beta^{\prime}}{\pi \alpha \beta^{\prime}} \text { and } \frac{\sigma_{m}^{\prime 2}}{\sigma_{m}^{2}}=\frac{\pi^{\prime} \alpha^{\prime} \beta^{\prime 2}\left[1+\alpha^{\prime}\left(1-\pi^{\prime}\right) \frac{1+d^{\prime}}{1-d^{\prime}}\right]}{\pi \alpha \beta^{2}\left[1+\alpha(1-\pi) \frac{1+d}{1-d}\right]}
$$

as shown in Wilks (1992). Although the ratios of mean monthly $\mathrm{P}$ and the corresponding variances can be estimated from GCM monthly output, 2 other subjective constraints are still required in order to determine the 4 parameters $\pi^{\prime}, d^{\prime}, \alpha^{\prime}$ and $\beta^{\prime}$ (Wilks 1992). For example, one of the simplest approaches is to assume no changes in the nature of the precipitation occurrence process (i.e. $d^{\prime} / d=\pi^{\prime} / \pi=1$ ), so that the only changes are in the gamma distribution parameters.

In daily temperature simulations, a multivariate firstorder autoregressive process is adopted in the Richardson type weather generator (Richardson 1981). Except for the additive adjustment for the means, adjustment of the parameters relies mainly on the relationship between the variance of monthly mean temperatures, $\operatorname{Var}(\bar{T})$ and the corresponding variance of daily mean temperature values, $\sigma_{d r}^{2}$ which is approximated as $\operatorname{Var}(\bar{T}) \approx \frac{\sigma_{d}^{2}}{N}\left(1+2 \sum_{k=1}^{\infty} \rho_{k}\right)($ Katz 1985), where $N$ is the number of days involved in calculating these statistics and $\rho_{k}$ is the autocorrelation function of the daily values. Applying a simplified assumption that the nature of daily temperature autocorrelations remains the same in a changed climate, the changes in interannual variability of monthly temperature are determined only by changes in the variance of the daily temperature series: $\frac{\operatorname{Var}\left(\bar{T}^{\prime}\right)}{\operatorname{Var}(\bar{T})}=\frac{\sigma_{d}^{\prime}}{\sigma_{d}}$ (Wilks 1992). For the simplest approach, this ratio can be applied to both daily Tx and Tn.

\subsection{Adjusting parameters using monthly statistics of daily values}

Daily GCM outputs are available from most climate modeling centers, in addition to monthly values. The statistics from daily GCM values can be used for the purpose of adjusting weather generator parameters. However, this does not imply that daily GCM values of climate variables are accurately reproduced for the present-day climate. For example, sequences of wet and dry days in GCMs may not be reliable for either the present climate or a changed future climate, as often significantly more wet days are found in GCM outputs, although this is related to the interpretation of P simulated by GCMs and can be addressed by applying an appropriate wet-day threshold. Therefore transition probabilities for a first-order or second-order Markov chain computed from these sequences may not be reliable either. Nevertheless, what we expect from daily GCM outputs are scenarios of climate change, i.e. ratios or differences between a future period and present-day values, rather than actual values. Since GCM outputs are only available on very coarse grids, introducing the changes in statistics on a grid directly to a location may not be suitable.

Using climate change scenarios on a daily time scale makes adjusting parameters easy for those weather generators that incorporate empirical distributions. For instance, in LARS-WG (version 3.0), ratios of mean length of wet and dry spells of a future climate to those of the baseline climate are used to adjust the scenarios of wet and dry spells for the future (Semenov \& Barrow 2002). The ratios can be computed from daily GCM outputs for P. Multiplying the duration of spells generated with empirical distributions for the baseline climate by the ratios can result in longer (if the ratios are $>1.0$ ) or shorter (if the ratios are $<1.0$ ) spells in the future than the baseline climate. These adjustments may have limitations. For example, the adjustment assumes that changes in the probability distributions of the wet and dry spells can be represented by the changes in their mean duration. In reality, changes in the probability distributions of the spells can be related to the changes in the shape of the distributions rather than to a mere shift to longer or shorter durations. Therefore, the methods for adjusting weather generator parameters based on daily GCM outputs can have significant ef- 
fects on the scenarios, and therefore investigating the proposed methodology is still worthwhile.

\subsection{Modification schemes for LARS-WG and AAFC-WG}

LARS-WG (version 3.0) uses a set of ratios and differences to perturb the weather generating process to obtain daily climate scenarios for a changed climate. Ratios are used for monthly P totals, monthly mean duration of wet and dry spells, standard deviations (SD) of daily mean temperatures; differences are used for monthly mean temperature and monthly mean radiation. Details for generating future climate scenarios with LARS-WG are elaborated in Semenov \& Barrow (2002).

AAFC-WG uses the second-order Markov chain to simulate sequences of wet and dry days, where a wet day is defined as daily $\mathrm{P} \geq 0.2 \mathrm{~mm}$. There are 4 transition probabilities that require modification: $p_{001}$ (probability of a wet day on Day $t$, given that Days $t-1$ and $t-2$ were dry), $p_{011}$ (probability of a wet day on Day $t$, given that Day $t-1$ was wet and Day $t-2$ was dry), $p_{101}$ (probability of a wet day on Day $t$, given Day $t-1$ was dry and Day $t-2$ was wet) and $p_{111}$ (probability of a wet day on Day $t$, given Days $t-1$ and $t-2$ were wet). Several approaches are possible: applying the same ratio of probabilities of a wet day to all 4 parameters; modify $p_{001}$ and $p_{101}$ with the ratios for $p_{01}$, and $p_{011}$ and $p_{111}$ with the ratios for $p_{11}$ i or perturb the 4 parameters with separate ratios respectively for $p_{001}$, $p_{101}, p_{011}$ and $p_{111}$. All these relevant ratios can be obtained from daily precipitation series of GCM outputs for the future period and the baseline period; however, these different schemes may have different effects on 'predicting' future wet and dry spells. This was examined with historical data for the representative stations in this study. Since daily Tx and Tn were conditioned on the occurrence of $\mathrm{P}$, simulated changes in temperature could also be associated with the 'predicted' wet and dry spells.

Daily amounts of $\mathrm{P}$ were simulated using empirical distributions in AAFC-WG. Daily amounts of P were first transformed using a logarithm and then standardized before counting cumulative frequencies for empirical distributions. Long-term mean and SD of the log-transformed daily amounts of $\mathrm{P}$ in a month were used in standardization. The logarithmic transformation and standardization improved the uniformity of the precipitation data. Since the logarithmic transformation helps to make the distribution of daily amounts of P closer to the normal distribution, mean and SD can represent the probability distribution of the log-transformed series better than the original data. Besides, as empirical distributions were built up with standardized series, modifications to these empirical distributions were not required for a changed climate.

As part of the comparison, daily amounts of $\mathrm{P}$ were also simulated by mixed exponential distributions. Mixed exponential distributions were found to be superior to the gamma distributions for non-zero daily $P$ (Wilks 1999). The 3 parameters $\left(\alpha, \beta_{1}, \beta_{2}\right)$ in mixed exponential distributions were estimated with the method of moments from the monthly mean, variance and coefficient of skewness of daily amounts of P. However, using standard probability distributions only affects statistics derived from daily P. The probability distribution of the wet and dry spells would not be affected by the probability distributions of daily $\mathrm{P}$, nor would daily $\mathrm{Tx}$ and Tn have an effect, since temperatures were conditional only on precipitation occurrence, not P. Ratios of the parameters computed from daily precipitation from GCM output for future and current climates can then be applied to the parameters estimated from current observations to form the parameters for a future changed climate.

Daily Tx and Tn and radiation are modeled in AAFCWG with a multivariate first-order autoregressive process. For simplicity, lag-0 and lag-1 correlation matrices can be kept unchanged for a changed climate. This implies that changes in inter-annual variability of monthly temperatures are only dominated by changes in the variance of the daily temperature series, which may not always be consistent with GCM simulations. This may underestimate inter-annual variability in future temperature scenarios; however, analyses on historical data showed less change in the variances of monthly temperatures than the daily values (cf. Section 3). Changes in mean and SD of daily Tx and Tn from daily GCM output can therefore be used to modify the annual cycles of the mean and SD interpolated by a spline procedure in AAFC-WG (Hayhoe 2000). It is possible to apply either unconditional changes to both wet and dry days or conditional changes separately to wet or dry days. The choice depends on how reliable the conditional changes in GCMs are considered to be. Applying separate changes to daily $\mathrm{Tx}$ and $\mathrm{Tn}$, instead of only using changes of daily mean temperature, seems necessary since historical trends indicate that daily $\mathrm{Tx}$ and $\mathrm{Tn}$ are changing in different ways (see Section 3).

\subsection{Strategy for assessing climate scenarios}

We used the weather generators calibrated with daily weather observations for 1911-1940 to generate 'future' daily climate scenarios for 1971-2000. This assumes that present climate (1971-2000, a changing/ changed climate relative to 1911-1940) is different from the baseline climate in 1911-1940. To generate 
'future' daily climate scenarios, differences and ratios of the statistics for the 2 periods were needed to modify weather generator parameters of the baseline climate to reflect a changed climate. This procedure is the same used to generate daily climate scenarios for a future changed climate, e.g. for 2040-2069, with weather generators calibrated from daily observations for a baseline climate such as 1961-1990. The only difference is that the 'climate change scenarios' in this study were computed from observations, while the climate change scenarios for developing future daily climate scenarios can only be estimated from daily GCM outputs.

The effect of different schemes for modifying the weather generator parameters on the performance of the weather generators was evaluated (cf. Table 1). Two different schemes for perturbing transition probabilities of the second-order Markov chain were applied to evaluate the effects on simulating wet and dry spells: (1) a full modification scheme applying separate multiplicative changes (ratios) for the 4 transition probabilities $p_{001}, p_{011}, p_{101}$ and $p_{111}$; (2) a partial modifica- tion scheme using multiplicative changes in transition probability $p_{01}$ for both $p_{001}$ and $p_{101}$, and $p_{11}$ for $p_{011}$ and $p_{111}$. As the full modification scheme seemed necessary (see Section 4), it was adopted for modeling precipitation occurrence in all other schemes for examining $\mathrm{P}$ and temperatures. Two schemes, AAFC-EM and AAFC-ME, were employed to evaluate simulations for daily $\mathrm{P}$ on wet days by using an empirical distribution and a mixed exponential distribution, respectively. Two other schemes, AAFC-CON and AAFC-UNC, were used to assess temperature simulations when the precipitation occurrence was determined by the full modification scheme and $\mathrm{P}$ was simulated by either an empirical distribution or a mixed exponential distribution. AAFC-CON applied different changes in mean and variance of daily $\mathrm{Tx}$ and $\mathrm{Tn}$, which were conditional on the precipitation occurrence. In contrast, changes were not conditional on the precipitation occurrence with AAFC-UNC, i.e. the same changes were assumed for either wet or dry days. LARS-WG uses a somewhat different methodology in simulating a changing/changed climate for precipitation occur-

Table 1. Brief description of the schemes for modifying weather generator parameters

\begin{tabular}{|c|c|c|c|c|}
\hline Variable & LARS-WG & AAFC-EM & AAFC-ME & AAFC-CON \\
\hline $\begin{array}{l}\text { Precipitation } \\
\text { occurrence }\end{array}$ & $\begin{array}{l}\text { Using multiplicative } \\
\text { changes in length } \\
\text { of wet and dry spells; } \\
\text { ratios being used to } \\
\text { multiply each value of } \\
\text { the generated wet or } \\
\text { dry spells }\end{array}$ & $\begin{array}{l}\text { Using multiplicative } \\
\text { changes in the transition } \\
\text { probabilities } \\
p_{001}, p_{011}, p_{101}, p_{111}\end{array}$ & Same as AAFC-EM & Same as AAFC-EM \\
\hline $\begin{array}{l}\text { Precipitation } \\
\text { amount }(\mathrm{P}) \text { on } \\
\text { a wet day }\end{array}$ & $\begin{array}{l}\text { Using multiplicative } \\
\text { changes in monthly } \\
\text { precipitation totals; } \\
\text { ratios being applied to } \\
\text { multiply each value of } \\
\text { the generated } \\
\text { precipitation }\end{array}$ & $\begin{array}{l}\text { Using additive changes in } \\
\text { means and multiplicative } \\
\text { changes in variance of } \\
\text { log-transformed daily P } \\
\text { on wet days; empirical } \\
\text { distribution of the log- } \\
\text { transformed and } \\
\text { standardised daily } \\
\text { P unmodified }\end{array}$ & $\begin{array}{l}\text { Using multiplicative } \\
\text { changes in monthly } \\
\text { mean, variance and } \\
\text { coefficient of skewness } \\
\text { of daily P to adjust the } \\
\text { corresponding statistics } \\
\text { and then the } 3 \\
\text { parameters }\left(\alpha, \beta_{1}, \beta_{2}\right) \text { of } \\
\text { the mixed exponential } \\
\text { distribution being } \\
\text { estimated for a } \\
\text { given month }\end{array}$ & Same as AAFC-EM \\
\hline $\begin{array}{l}\text { Maximum } \\
\text { temperature } \\
(\mathrm{Tx})\end{array}$ & $\begin{array}{l}\text { Using additive changes } \\
\text { in monthly mean } \\
\text { temperature; being added } \\
\text { to each value of daily } \\
\text { Tx generated in a month; } \\
\text { using multiplicative } \\
\text { changes in SD of daily } \\
\text { mean temperatures in } \\
\text { a month }\end{array}$ & $\begin{array}{l}\text { Using additive changes } \\
\text { in mean Tx of a given } \\
\text { month and multiplicative } \\
\text { changes in corresponding } \\
\text { SD to modify the annual } \\
\text { cycle of daily Tx; no } \\
\text { changes to the parameters } \\
\text { in the first-order multi- } \\
\text { variate regression models }\end{array}$ & Same as AAFC-EM & $\begin{array}{l}\text { Similar to AAFC-EM } \\
\text { but all changes are } \\
\text { separately for wet } \\
\text { days and dry days }\end{array}$ \\
\hline $\begin{array}{l}\text { Minimum } \\
\text { temperature } \\
\text { (Tn) }\end{array}$ & $\begin{array}{l}\text { Same changes as } \\
\text { applied to Tx }\end{array}$ & $\begin{array}{l}\text { Similar to Tx but } \\
\text { changes in Tn }\end{array}$ & Same as AAFC-EM & $\begin{array}{l}\text { Similar to AAFC-EM } \\
\text { but all changes are } \\
\text { separately for wet } \\
\text { and dry days }\end{array}$ \\
\hline
\end{tabular}


rence, $\mathrm{P}$ on wet days, and daily temperatures; thus, it was employed in this study as a reference tool. Since AAFC-UNC uses the same modification to temperatures as AAFC-EM, it is not listed in Table 1. Details about generating climate scenarios for a changing/ changed climate using LARS-WG are in Semenov \& Barrow (2002). Only precipitation and daily Tx and Tn were included in this study, as long-term historical observations for radiation were not available.

Statistical tests are often employed to evaluate the capabilities of the stochastic weather generators in simulating statistical properties of observed weather data, for example, the $\chi^{2}$ test and the 2-sample Kolmogorov-Smirnov (K-S) test are used to test the null hypothesis that the observed and generated series were drawn from the same probability distribution; the $t$-test and the $F$-test are performed to test whether the differences are significant for the mean and variance obtained from observations and simulations (Semenov et al. 1998, Hayhoe 2000, Semenov \& Barrow 2002, Qian et al. 2004a). However, daily weather data within a month, such as temperatures, often have strong serial correlation. This serial correlation in the data series violates the basic assumption of conventional statistical tests that the data are derived in independent experiments. Besides, some tests (e.g. the $t$-test and the $F$-test) require that the data be normally distributed. This implies that these tests may not be adequate if the data are not normally distributed, even if no significant serial correlation exists. An example would be untransformed daily $\mathrm{P}$ on wet days. For the tests applied to monthly values in weather generator studies, serial correlation may not be strong, but normality can sometimes be in question.

Resampling tests (Wilks 1995) were used in this study to avoid the difficulties in applying conventional statistical tests. Resampling procedures for preserving serial correlation within a month in daily weather series in the tests are described in Qian et al. (2004b). The test statistic for probability distributions takes the same form as in the 2-sample K-S test, where the largest difference $D_{m n}=\max _{x}\left|F_{m}\left(x_{1}\right)-F_{n}\left(x_{2}\right)\right|$ between the 2 empirical cumulative distribution functions (CDFs), is estimated from the observed weather series $\left(x_{11}, x_{12}, \ldots . ., x_{1 m}\right)$ and from the synthetic series $\left(x_{21}\right.$, $\left.x_{22}, \ldots, x_{2 n}\right)$ generated by stochastic weather generators. The test statistic for the means is the absolute difference between the means estimated from the 2 samples, $D=\left|\frac{1}{m} \sum_{i=1}^{m} x_{1 i}-\frac{1}{n} \sum_{j=1}^{n} x_{2 j}\right|$. The test statistic for the variances is similar to the one for the F-test, where $F=\frac{F_{1}}{F_{2}}$ if $F_{2} \leq F_{1}$ and $F=\frac{F_{2}}{F_{1}}$ if $F_{2}>F_{1}$, $F_{1}=\frac{1}{m-1} \sum_{i=1}^{m}\left(x_{1 i}-\frac{1}{m} \sum_{i=1}^{m} x_{1 i}\right)^{2}$ and $F_{2}=\frac{1}{n-1} \sum_{j=1}^{n}\left(x_{2 j}-\frac{1}{n} \sum_{j=1}^{n} x_{2 j}\right)^{2}$.

Critical values of the test statistics at the $5 \%$ significance level were then determined from the empirical distributions of the test statistics in resampling tests. These confirmed that applying the $t$-test and the $F$-test to the log-transformed daily $\mathrm{P}$ was effective. Resampling tests also showed that the $t$-test and the $F$-test could be applied to the agroclimatic indices in this study.

\section{OBSERVED CHANGES BETWEEN THE 30 YEAR PERIODS}

A basis of the study is the determination that the climates were indeed significantly different in terms of statistical properties, especially for daily values, between 1971-2000 vs. 1911-1940. However, the causes are not important in this study, as we do not intend to detect and interpret climate changes from observations.

Significant differences were found more often in daily weather series (Table 2) than in their corresponding monthly values except for minimum temperature (Table 3). This may imply that using changes in monthly values may not necessarily reflect changes in the corresponding daily values. The $30 \mathrm{yr}$ mean of daily precipitation on wet days, daily $\mathrm{Tx}$ and $\mathrm{Tn}$ for 1971-2000 are listed in Table 4, in comparison to the corresponding values for 1911-1940. Significant differences were often found in the means of daily Tn and

Table 2. Number of months showing significant differences in probability distributions (D), mean (M) and variances (V) for daily precipitation (P), daily maximum (Tx) and minimum (Tn) temperature, and daily temperature range (DTR) between 1971-2000 and 1911-1940

\begin{tabular}{|c|c|c|c|c|c|c|c|c|c|c|c|c|}
\hline & \multicolumn{3}{|c|}{$-\mathrm{P}(\mathrm{mm})-$} & \multicolumn{3}{|c|}{$-\mathrm{Tx}\left({ }^{\circ} \mathrm{C}\right)-$} & \multicolumn{3}{|c|}{$-\operatorname{Tn}\left({ }^{\circ} \mathrm{C}\right)-$} & \multicolumn{3}{|c|}{$-\operatorname{DTR}\left({ }^{\circ} \mathrm{C}\right)-$} \\
\hline & $\mathrm{D}$ & $\mathrm{M}$ & V & $\mathrm{D}$ & M & $\mathrm{V}$ & $\mathrm{D}$ & $\mathrm{M}$ & V & $\mathrm{D}$ & M & $\mathrm{V}$ \\
\hline Ottawa & 12 & 4 & 0 & 3 & 2 & 2 & 10 & 10 & 1 & 11 & 10 & 2 \\
\hline Regina & 6 & 2 & 0 & 3 & 1 & 1 & 7 & 6 & 2 & 9 & 7 & 10 \\
\hline Toronto & 4 & 2 & 2 & 2 & 1 & 3 & 11 & 11 & 1 & 12 & 12 & 9 \\
\hline
\end{tabular}


Table 3. Number of months showing significant differences in mean (M) and variances (V) of total precipitation (P), monthly mean maximum (Tx) and minimum (Tn) temperature and monthly mean daily temperature range (DTR) temperature range between 1971-2000 and 1911-1940

\begin{tabular}{|lccccrrrr|}
\hline & \multicolumn{3}{c}{$\mathrm{P}(\mathrm{mm})$} & \multicolumn{2}{c}{$\operatorname{Tx}\left({ }^{\circ} \mathrm{C}\right)$} & \multicolumn{2}{c|}{$\operatorname{Tr}\left({ }^{\circ} \mathrm{C}\right)$} & \multicolumn{2}{c|}{$\mathrm{DTR}\left({ }^{\circ} \mathrm{C}\right)$} \\
& $\mathrm{M}$ & $\mathrm{V}$ & $\mathrm{M}$ & $\mathrm{V}$ & $\mathrm{M}$ & $\mathrm{V}$ & $\mathrm{M}$ & $\mathrm{V}$ \\
\hline Ottawa & 0 & 0 & 2 & 0 & 10 & 1 & 10 & 3 \\
Regina & 1 & 1 & 0 & 2 & 6 & 0 & 7 & 3 \\
Toronto & 0 & 2 & 1 & 0 & 11 & 1 & 12 & 6 \\
\hline
\end{tabular}

Table 4. Thirty yr means of daily precipitation (P) on wet days, daily maximum (Tx) and minimum (Tn) temperature for 1971-2000 in comparison with 1911-1940. *Significantly different from the corresponding values for 1911-1940; $\mathrm{p}<0.05$

\begin{tabular}{|c|c|c|c|c|c|c|}
\hline & \multicolumn{3}{|c|}{$1911-1940$} & \multicolumn{3}{|c|}{$1971-2000$} \\
\hline & $\begin{array}{c}\mathrm{P} \\
(\mathrm{mm})\end{array}$ & $\begin{array}{c}\mathrm{Tx} \\
\left({ }^{\circ} \mathrm{C}\right)\end{array}$ & $\begin{array}{l}\mathrm{Tn} \\
\left({ }^{\circ} \mathrm{C}\right)\end{array}$ & $\begin{array}{c}\mathrm{P} \\
(\mathrm{mm})\end{array}$ & $\begin{array}{c}\mathrm{Tx} \\
\left({ }^{\circ} \mathrm{C}\right)\end{array}$ & $\begin{array}{l}\mathrm{Tn} \\
\left({ }^{\circ} \mathrm{C}\right)\end{array}$ \\
\hline \multicolumn{7}{|c|}{ Ottawa } \\
\hline Jan & 5.9 & -6.2 & -16.2 & $3.9^{*}$ & -6.1 & -14.8 \\
\hline Feb & 5.8 & -5.6 & -16.3 & $4.2^{*}$ & $-3.9^{*}$ & $-13.2^{*}$ \\
\hline Mar & 6.0 & 0.6 & -8.9 & 5.2 & $2.1^{*}$ & $-7.0^{*}$ \\
\hline Apr & 6.2 & 10.1 & -0.6 & 5.4 & 10.9 & $1.1^{*}$ \\
\hline May & 6.2 & 19.0 & 6.4 & 6.0 & 19.1 & $8.0^{*}$ \\
\hline Jun & 7.3 & 24.1 & 11.5 & 7.1 & 23.8 & $13.0^{*}$ \\
\hline Jul & 7.6 & 26.9 & 14.2 & 7.2 & 26.4 & $15.5^{*}$ \\
\hline Aug & 7.0 & 25.5 & 12.9 & 7.3 & 25.0 & $14.3^{*}$ \\
\hline Sep & 6.9 & 20.4 & 8.8 & 6.2 & 19.7 & $9.7^{*}$ \\
\hline Oct & 6.3 & 12.9 & 2.9 & 5.6 & 12.6 & $3.7^{*}$ \\
\hline Nov & 6.3 & 4.0 & -3.5 & $5.2^{*}$ & 4.9 & $-1.9^{*}$ \\
\hline Dec & 5.7 & -3.8 & -11.8 & $4.6^{*}$ & -2.9 & -10.3 \\
\hline \multicolumn{7}{|c|}{ Regina } \\
\hline Jan & 1.7 & -12.1 & -23.0 & $1.4^{*}$ & -10.7 & -21.6 \\
\hline Feb & 1.5 & -9.1 & -20.4 & 1.4 & -6.7 & $-17.1^{*}$ \\
\hline Mar & 2.1 & -1.4 & -13.1 & 2.2 & 0.3 & $-10.3^{*}$ \\
\hline Apr & 2.4 & 10.4 & -3.1 & 2.8 & 10.9 & $-2.0^{*}$ \\
\hline May & 4.7 & 19.1 & 3.2 & 5.0 & 18.8 & $4.6^{*}$ \\
\hline Jun & 6.7 & 23.3 & 8.4 & 5.8 & 23.2 & $9.6^{*}$ \\
\hline Jul & 5.8 & 27.0 & 11.1 & 5.9 & $25.6^{*}$ & 11.8 \\
\hline Aug & 5.1 & 25.7 & 9.2 & 4.5 & 25.3 & $10.7^{*}$ \\
\hline Sep & 4.5 & 19.4 & 4.1 & 3.9 & 18.7 & 4.6 \\
\hline Oct & 3.6 & 10.9 & -2.3 & 3.2 & 11.5 & -2.0 \\
\hline Nov & 2.2 & 0.3 & -10.6 & $1.6^{*}$ & -0.2 & -10.7 \\
\hline Dec & 1.8 & -7.8 & -18.0 & 1.6 & -7.9 & -18.5 \\
\hline \multicolumn{7}{|c|}{ Toronto } \\
\hline Jan & 4.5 & -0.6 & -8.2 & 4.0 & -1.1 & -7.3 \\
\hline Feb & 4.0 & -1.1 & -8.9 & 4.3 & -0.2 & $-6.3^{*}$ \\
\hline Mar & 4.4 & 3.7 & -4.2 & 5.2 & 4.6 & $-2.0^{*}$ \\
\hline Apr & 5.4 & 10.8 & 1.8 & 5.7 & 11.2 & $3.8^{*}$ \\
\hline May & 5.6 & 18.3 & 7.4 & 6.0 & 18.4 & $9.9^{*}$ \\
\hline Jun & 6.3 & 23.8 & 12.6 & 6.5 & 23.5 & $14.7^{*}$ \\
\hline Jul & 7.1 & 27.1 & 15.9 & 6.6 & 26.4 & $17.9^{*}$ \\
\hline Aug & 7.3 & 25.8 & 15.0 & 7.6 & 25.3 & $17.3^{*}$ \\
\hline Sept & 6.0 & 21.5 & 11.3 & $7.8^{*}$ & $20.7^{*}$ & $13.2^{*}$ \\
\hline Oct & 5.5 & 14.5 & 5.5 & 5.7 & 13.8 & $7.3^{*}$ \\
\hline Nov & 5.0 & 7.2 & 0.3 & 6.0 & 7.4 & $2.2^{*}$ \\
\hline Dec & 4.0 & 1.3 & -5.2 & $4.9^{*}$ & 1.8 & $-3.6^{*}$ \\
\hline
\end{tabular}

there were also some cases for daily Tx and precipitation. Differences in mean and variance of monthly values were usually not significant, except in the mean of monthly mean Tn. More significant changes were found in Tn than in Tx. This implies that daily temperature range (DTR) could be significantly different between the 2 periods. Resampling tests confirmed this inference, as most months could not pass the tests for equal means in both daily and monthly values of DTR. Inconsistent changes in $\mathrm{Tx}$ and $\mathrm{Tn}$ may also have important implications for modifications that apply the same changes from daily mean temperatures to both Tx and Tn when the weather generator parameters are perturbed for a changed climate. Such an approach may not be suitable, since DTR in the scenarios can be affected, as can Tx and Tn.

Statistics of the wet and dry spells may be different between the $30 \mathrm{yr}$ periods. It was rarely observed that there were differences in the mean lengths of the wet or dry spells, while the distributions of their relative frequencies remained unchanged. Instead, the distributions often changed while mean length varied little. For example, $1 \mathrm{~d}$ spells had the highest relative frequency for May wet spells at Toronto during 1911-1940, but the highest frequency was shifted to 2 d spells during 1971-2000, while mean lengths were 2.0 and $2.1 \mathrm{~d}$ respectively. Changes occurred more often in both the mean length and the distribution (Fig. 1). The relative frequencies of $1 \mathrm{~d}$ wet spells decreased dramatically, but remained the highest in all lengths of wet spells, while frequencies for other lengths increased from 1911-1940 for some cases shown in Fig. 1. This indicates changes in mean length (e.g. mean length of September wet spells at Ottawa increased from 1.8 to $2.5 \mathrm{~d}$ ), but it does not imply a simple shift. Changes in the distributions of the spell durations accompanied by changes in mean length might not be sufficiently reflected by changes in mean length of wet and dry spells; however, it is possible that changes in transition probabilities (probably a higher order) would be able to reflect such changes in the distributions of the spell durations. For instance, second-order transition probabilities $p_{011}$ increased from 0.466 to 0.649 in the case of May wet spells at Toronto during 1971-2000 compared to 1911-1940.

Average values of the agroclimatic indices are listed in Table 5. It appears that crop growing conditions were significantly different in 1971-2000 compared to 1911-1940. The recent period generally had an earlier last frost date in spring (FS), earlier last killing frost date in spring (KFS), later first frost date in fall (FF) and later first killing frost date in fall (KFF). These results were consistent with the higher numbers of frost-free days (FFD), growing degree-days (GDD), effective growing degree-days (EGDD) and crop heat units 
Wet spells in January at Ottawa

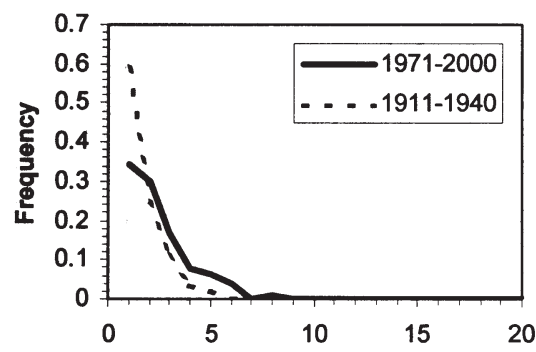

Wet spells in April at Ottawa

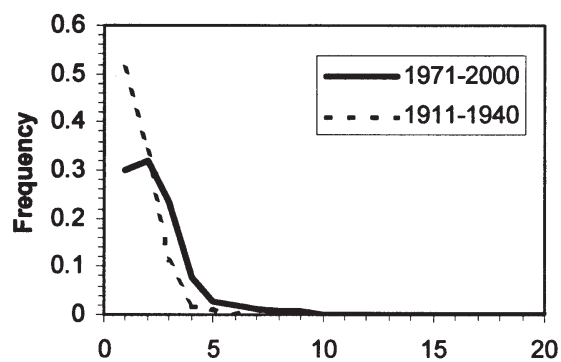

Wet spells in December at Ottawa

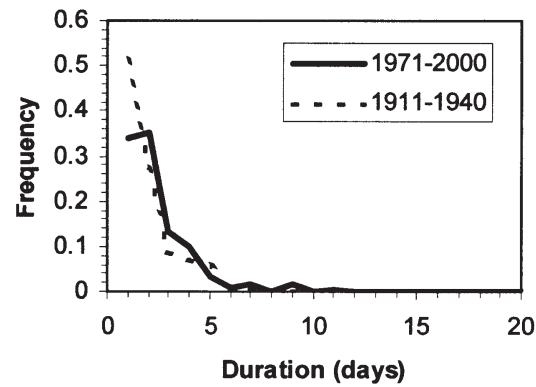

\section{Wet spells in February at Ottawa}

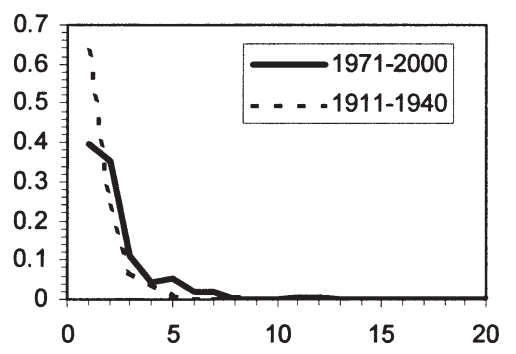

Wet spells in September at Ottawa

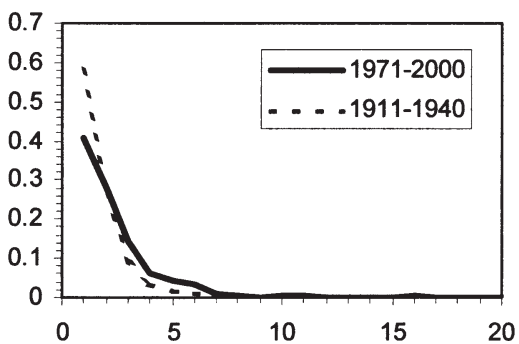

Dry spells in August at Regina

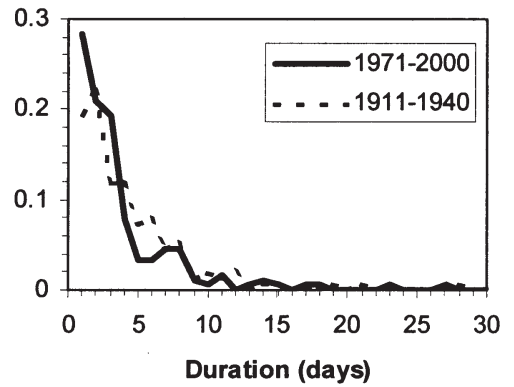

Wet spells in March at Ottawa

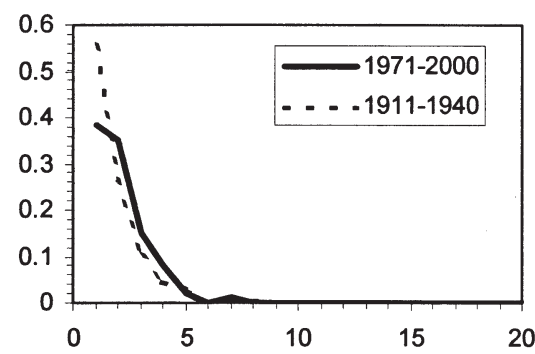

Dry spells in December at Ottawa

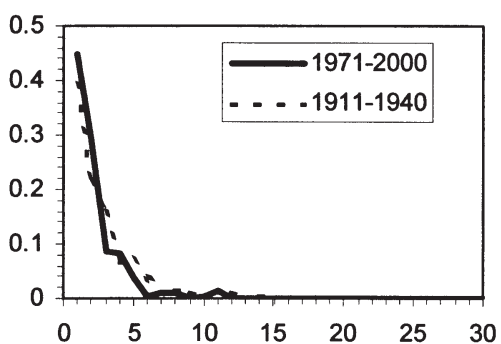

Wet spells in May at Toronto

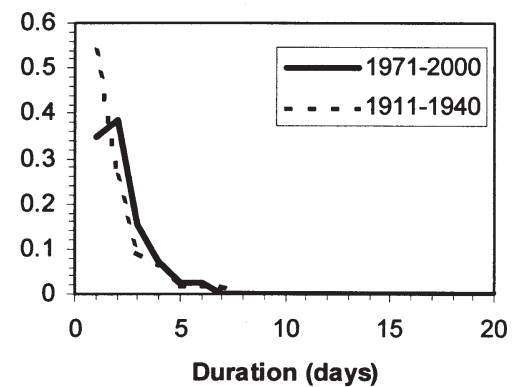

Fig. 1. Relative frequencies of wet and dry spells at Ottawa, Toronto and Regina for 1971-2000, in comparison with 1911-1940

(CHU) in the recent 1971-2000 period. The changes reflected the fact that temperatures were higher, especially the minimum temperature. The precipitation deficit/surplus (PDS) for the growing season was lower in the recent $30 \mathrm{yr}$ than in 1911-1940, reflecting a reduction in the water deficit for the crop growing season. No significant difference was found in variances of the agroclimatic indices between the 2 periods.

The above analysis indicated that there were significant differences in the relevant statistics of daily climate variables and agroclimatic indices between the 30 yr periods. Therefore, the 2 periods were adequate for the purpose of this study.

\section{RESULTS AND DISCUSSION}

Results from the experiments that used different schemes to modify the parameters of AAFC-WG cali- brated with daily weather data for 1911-1940 to simulate weather series in 1971-2000 are presented and discussed in this section, together with corresponding results from LARS-WG. The analyses were focused on statistical properties of the synthetic weather data for a changed climate.

\subsection{Dry and wet spells}

The 4 transition probabilities for the second-order Markov chain in AAFC-WG determine the wet and dry day sequences in a month. Figs. 2 to 4 demonstrate how the modifications to all transition probabilities improve the simulations of the relative frequencies of dry and wet spells. The same cases as in Fig. 1 were used, to verify the simulations for the cases where significant differences were detected between the 2 periods. Simulations where all 4 transition probabilities 
Table 5. Agroclimatic indices (30 yr mean). Dates: day of the year. ${ }^{*}$ Significantly different from the corresponding values for 1911-1940; $\mathrm{p}<0.05$

\begin{tabular}{|c|c|c|}
\hline & $\begin{array}{c}1911- \\
1940\end{array}$ & $\begin{array}{c}1971- \\
2000\end{array}$ \\
\hline \multicolumn{3}{|l|}{ Ottawa } \\
\hline Last date of frost in spring (FS) & 132 & $118^{*}$ \\
\hline First date of frost in fall (FF) & 271 & $277^{*}$ \\
\hline Last date of killing frost in spring (KFS) & 120 & $109^{*}$ \\
\hline First date of killing frost in fall (KFF) & 285 & 289 \\
\hline Frost free days (FFD) & 138 & $158^{*}$ \\
\hline Growing degree-days (GDD) & 1986 & $2097^{*}$ \\
\hline Effective growing degree-days (EGDD) & 1831 & $1955^{*}$ \\
\hline Corn heat units (CHU) & 2744 & $2887^{*}$ \\
\hline Precipitation deficit (mm) & 229 & $122^{*}$ \\
\hline \multicolumn{3}{|l|}{ Regina } \\
\hline Last date of frost in spring (FS) & 154 & $139^{*}$ \\
\hline First date of frost in fall (FF) & 251 & 256 \\
\hline Last date of killing frost in spring (KFS) & 139 & $130^{*}$ \\
\hline First date of killing frost in fall (KFF) & 263 & 267 \\
\hline Frost free days (FFD) & 96 & $116^{*}$ \\
\hline Growing degree-days (GDD) & 1623 & 1681 \\
\hline Effective growing degree-days (EGDD) & 1445 & $1517^{*}$ \\
\hline Corn heat units (CHU) & 2080 & $2215^{*}$ \\
\hline Precipitation deficit (mm) & 396 & $328^{*}$ \\
\hline \multicolumn{3}{|l|}{ Toronto } \\
\hline Last date of frost in spring (FS) & 120 & $106^{*}$ \\
\hline First date of frost in fall (FF) & 292 & $304^{*}$ \\
\hline Last date of killing frost in spring (KFS) & 107 & $98^{*}$ \\
\hline First date of killing frost in fall (KFF) & 306 & $318^{*}$ \\
\hline Frost free days (FFD) & 171 & $196^{*}$ \\
\hline Growing degree-days (GDD) & 2211 & $2401^{*}$ \\
\hline Effective growing degree-days (EGDD) & 2118 & $2336^{*}$ \\
\hline Corn heat units (CHU) & 3012 & $3435^{*}$ \\
\hline Precipitation deficit (mm) & 224 & $81^{*}$ \\
\hline
\end{tabular}

were modified with separate ratios most often reproduced the relative frequencies of wet and dry spells much better than simulations where only changes to the first order transition probabilities were applied. It also appeared that modification of the mean length of wet and dry spells that was used in LARS-WG might not be sufficient to simulate changes in the relative frequencies of wet and dry spells, at least for the stations used in this study.

\subsection{Daily precipitation series}

It was expected that statistical properties such as probability distribution, mean and SD of the generated weather series could be made to correspond to a changed climate by modifying the parameters involved in the weather generators. This is important, because the statistical properties of the weather series in the changed climate may be different from those of the weather series used to calibrate the weather gener- ators. Moreover, impact models may be sensitive to these statistical properties. The modifications to the weather generator parameters should account for the changes, so that only minimal differences are found between the simulated and the observed weather series for the changed climate. Obviously the mean and SD of a weather series could be better simulated than its corresponding probability distributions, as modifications to the weather generator parameters were often associated with mean and SD of the weather variables.

The simulated daily data were very good for mean and SD of daily $\mathrm{P}$ and for monthly precipitation totals derived from daily values (Table 6). No significant differences were found in mean and SD of daily $\mathrm{P}$ for the scheme AAFC-EM in almost all cases. Very few cases of significant differences were found in SD of monthly precipitation totals, while all cases passed the tests for equal means in monthly precipitation totals for AAFCEM. For the scheme AAFC-ME, AAFC-WG using the mixed exponential distributions had slightly better performance for the mean and variance than AAFCEM. Simulations by LARS-WG also showed good reproductions of mean and variance of precipitation for daily and monthly values.

Probability distributions of daily $\mathrm{P}$ on wet days appeared to be the most difficult property to simulate by modifying the weather generator parameters. None of the 3 methods, LARS-WG, AAFC-WG with mixed exponential distributions (AAFC-ME) or empirical distributions (AAFC-EM), showed consistent advantages in reproducing probability distributions of daily $P$. Quite a few months failed in the resampling tests for probability distributions (Table 6), although the majority of the cases could pass the statistical tests. Q-Q plots of daily P generated by AAFC-WG with the 2 different methods versus observations for January and July also showed that no consistent advantages could be found for either method (Figs. 5 \& 6). The methodology for LARS-WG (Fig. 7) also resulted in similar outcomes.

The appropriate modification method required to accurately specify the probability distribution for a changed future climate may not be known exactly in advance. For example, using mixed exponential distributions with modified parameters may be able to accurately produce the probability distributions if we have the information that daily $\mathrm{P}$ will continue to be exponentially distributed in a future climate. However, this kind of information may still be lacking from GCM outputs. Using adjusted parameters for mixed exponential distributions in our experiments did not improve the goodness-of-fit of daily precipitation probability distribution. Nevertheless, outcomes of no significant difference for the probability distribution of daily precipitation were still found for a weak majority of 


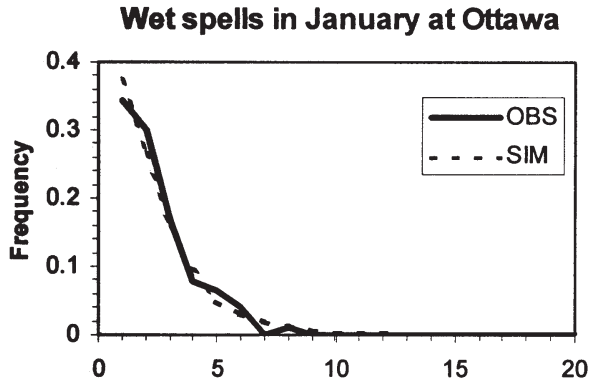

Wet spells in April at Ottawa

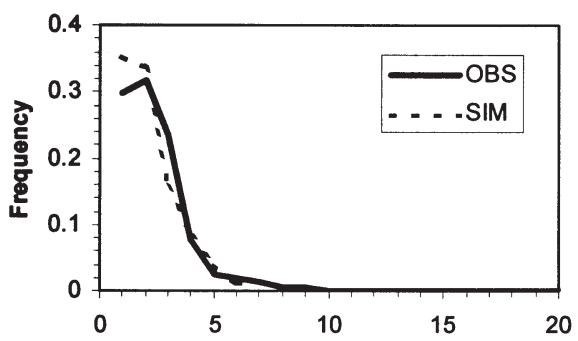

Wet spells in December at Ottawa

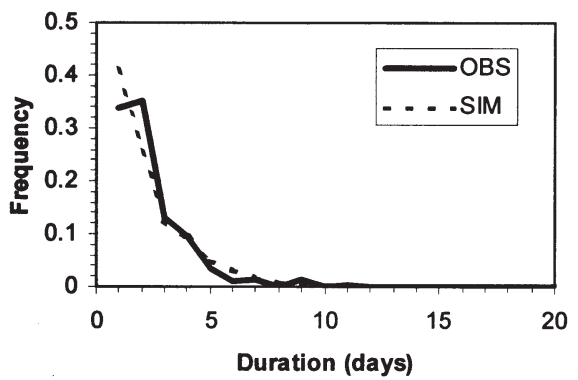

Wet spells in February at Ottawa

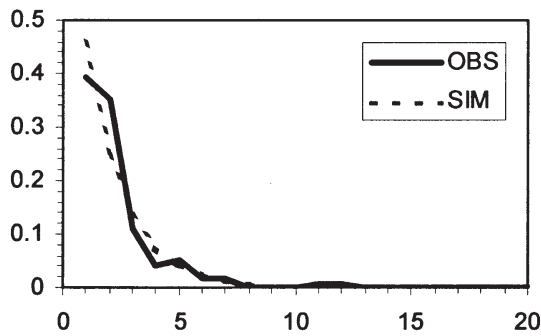

Wet spells in September at Ottawa

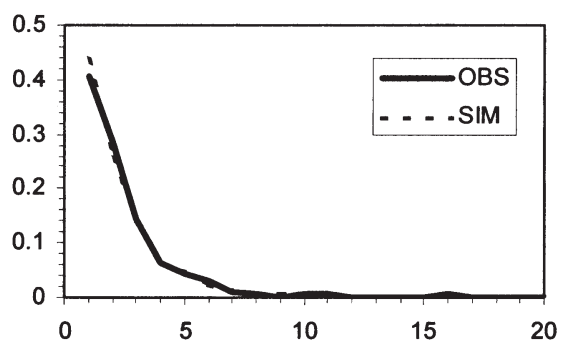

Dry spells in August at Regina

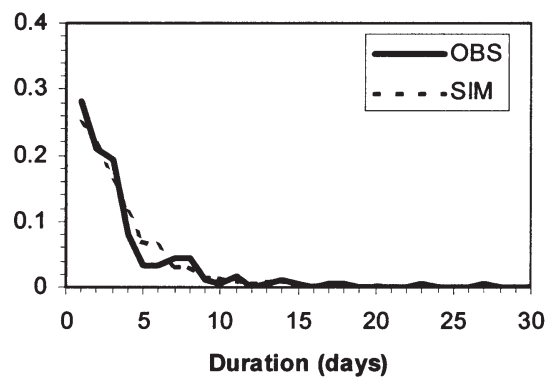

Wet spells in March at Ottawa

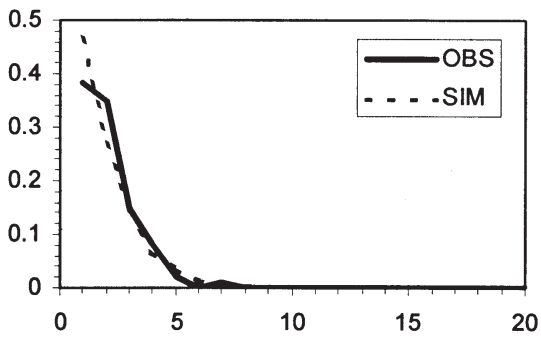

Dry spells in December at Ottawa

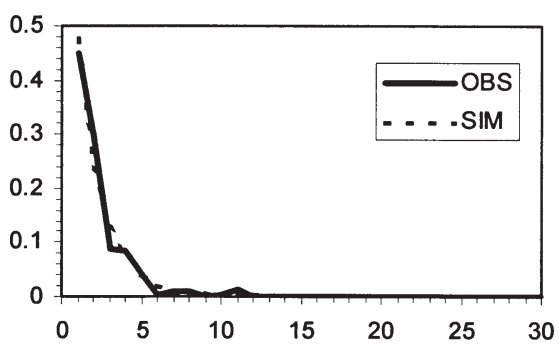

Wet spells in May at Toronto

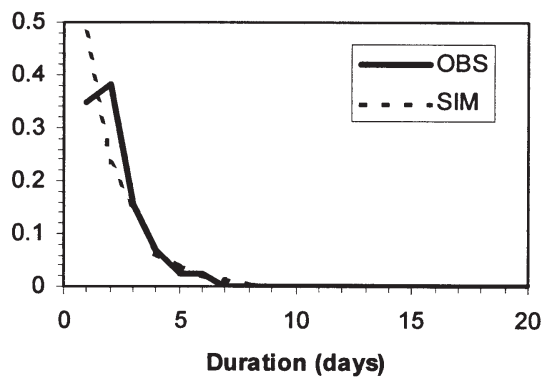

Fig. 2. Simulations of wet and dry spells by AAFC-WG with partially modified transition probabilities for 1971-2000, in comparison with observations

Table 6. Number of months with significant differences between observed and simulated data with regard to distribution (D), mean (M) and variance (V) of daily and monthly precipitation totals for 1971-2000. AAFC-WG tested with mixed exponential distributions (AAFC-ME) and empirical distributions (AAFC-EM)

\begin{tabular}{|lccccc|} 
& \multicolumn{3}{c}{ Daily } & \multicolumn{3}{c|}{ Monthly } \\
& $\mathrm{D}$ & $\mathrm{M}$ & $\mathrm{V}$ & $\mathrm{M}$ & $\mathrm{V}$ \\
\hline Ottawa & & & & & \\
LARS-WG & 9 & 0 & 6 & 0 & 3 \\
AAFC-ME & 5 & 0 & 0 & 0 & 0 \\
AAFC-EM & 3 & 0 & 0 & 0 & 2 \\
Regina & & & & & \\
LARS-WG & 6 & 0 & 2 & 0 & 2 \\
AAFC-ME & 5 & 0 & 0 & 0 & 1 \\
AAFC-EM & 6 & 0 & 0 & 0 & 1 \\
Toronto & & & & & \\
LARS-WG & 2 & 0 & 0 & 0 & 2 \\
AAFC-ME & 5 & 0 & 0 & 0 & 0 \\
AAFC-EM & 5 & 0 & 0 & 0 & 0 \\
\hline
\end{tabular}

months and stations involved in this study. Taking the uncertainties from climate modeling and emission scenarios for the greenhouse gases into account, this performance of the methodology should be acceptable for impact studies.

\subsection{Daily maximum and minimum temperatures (Tx and Tn)}

Daily Tx and Tn are conditional on the weather status in most weather generators, i.e. mean and variance are different when a day is wet or dry. It follows that we need to assess the impact of introducing changes in mean and variance separately on wet and dry days, rather than applying the same unconditional changes to both wet and dry days. This is interesting, because mean and variance of daily temperatures on wet days in climate models may not be reliable. We 
Wet spells in January at Ottawa

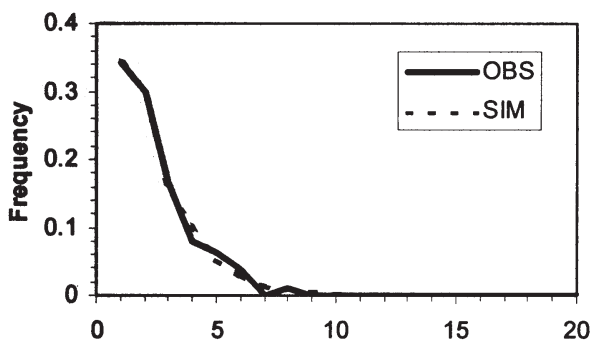

Wet spells in April at Ottawa

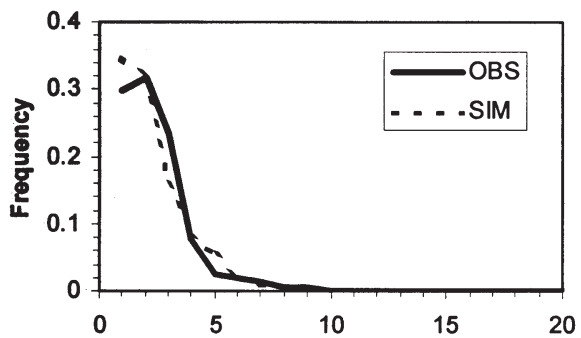

Wet spells in December at Ottawa

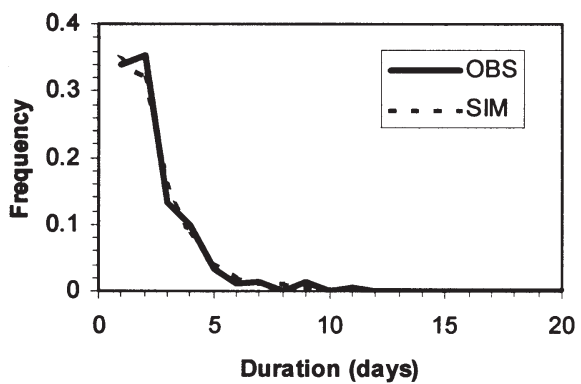

Wet spells in February at Ottawa

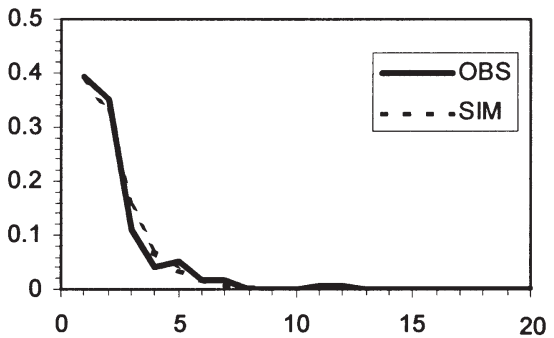

Wet spells in September at Ottawa

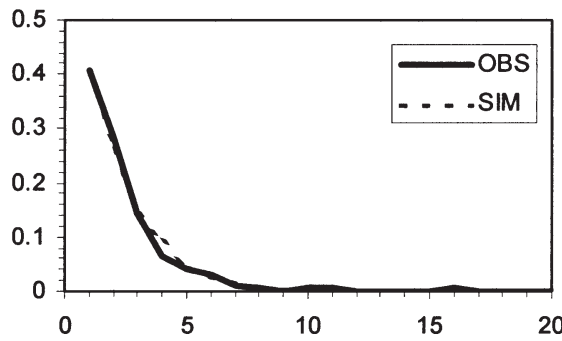

Dry spells in January at Regina

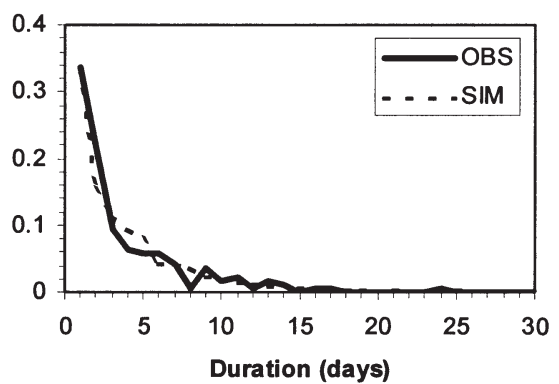

Wet spells in March at Ottawa

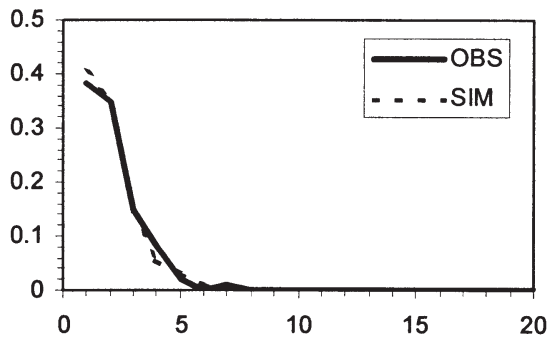

Dry spells in December at Ottawa

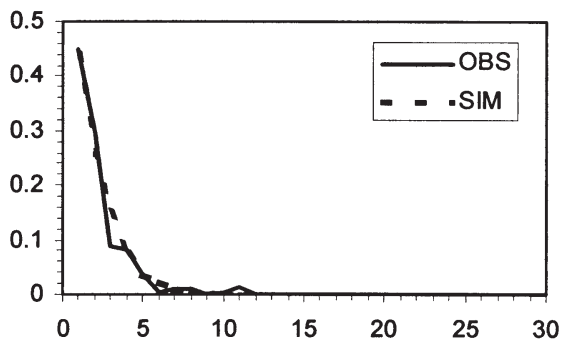

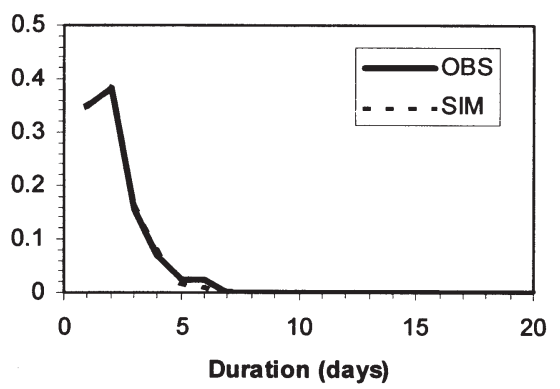

Fig. 3. Simulations of wet and dry spells by AAFC-WG with fully modified transition probabilities for 1971-2000, in comparison with observations

found that GCMs (e.g. CGCM1 of the Canadian Centre for Climate Modelling and Analysis, and HadCM3 of the Hadley Centre for Climate Prediction and Research) commonly produce too many wet days in comparison to observations in Canada, when daily precipitation data from GCMs were interpreted as grid-point values instead of grid-box averages. Using an appropriate wet-day threshold for precipitation in GCMs, rather than the conventional thresholds for observations might result in a more realistic reproduction of the observed wet-day occurrence (Wilby \& Wigley 2002).

AAFC-WG simulated daily Tx and Tn satisfactorily with either modification scheme (Tables $7 \&$ 8). No significant difference was detected from all the tests conducted for 3 stations and 12 months for distribution, mean and variance of daily values. In contrast, more than $60 \%$ of the cases for daily Tx and Tn from
LARS-WG failed to pass the test for distribution. The simulations for daily Tn were the poorest, as many cases ( $44 \%$ of the cases) could not even pass the test for mean and variance. Failure to reproduce statistical properties for daily temperature by LARS-WG might be related to its modification procedure for the weather generator parameters, i.e. applying the same changes in mean temperature to both $\mathrm{Tx}$ and $\mathrm{Tn}$. However, the unsatisfactory reproduction of the statistical properties to daily temperature could also be associated with the assumption that daily Tx and Tn follow normal distributions in LARS-WG (Qian et al. 2004a).

Q-Q plots of daily Tx and Tn in January and July generated by AAFC-WG with the same changes applied to both wet and dry days, and by LARS-WG against observations show that simulations from AAFC-WG (Fig. 8) were much closer to the observa- 
Wet spells in January at Ottawa

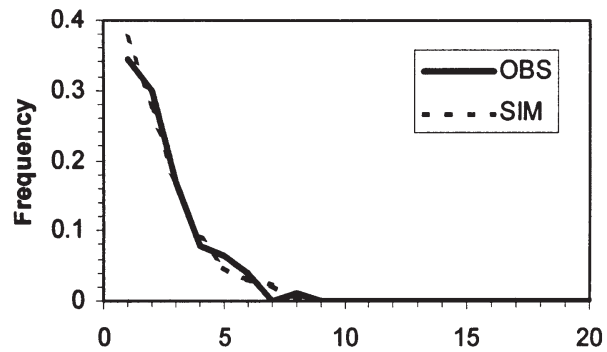

Wet spells in April at Ottawa

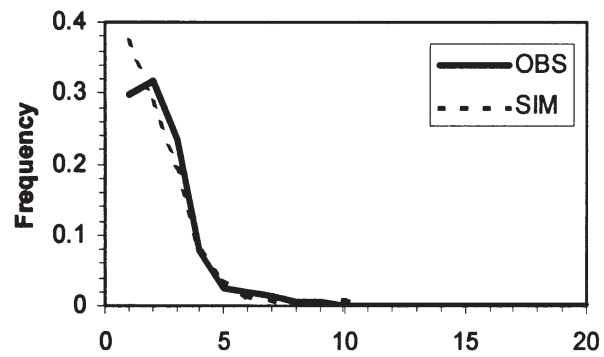

Wet spells in December at Ottawa

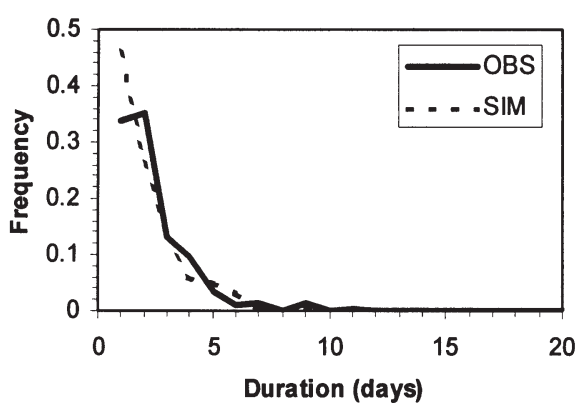

Wet spells in February at Ottawa

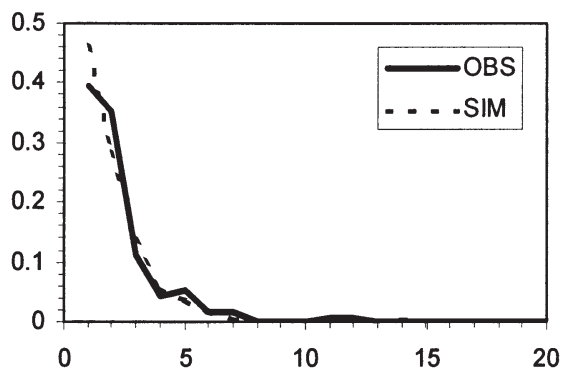

Wet spells in September at Ottawa

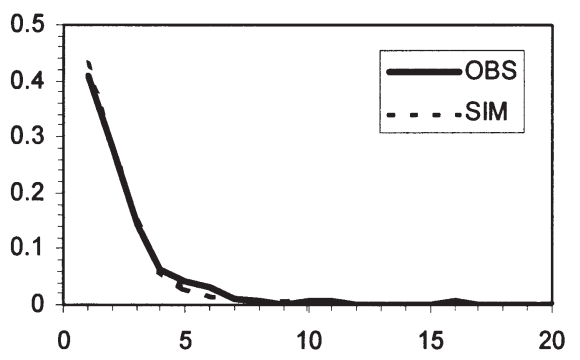

Dry spells in August at Regina

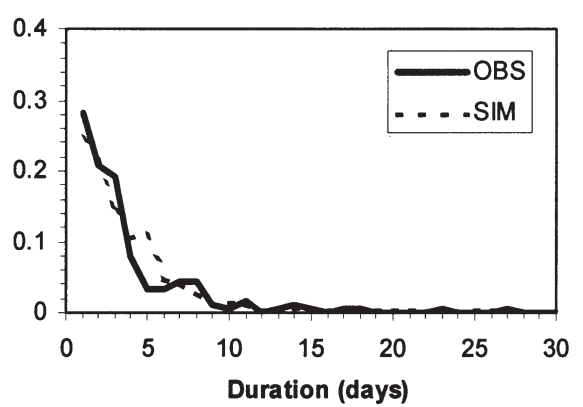

Wet spells in March at Ottawa

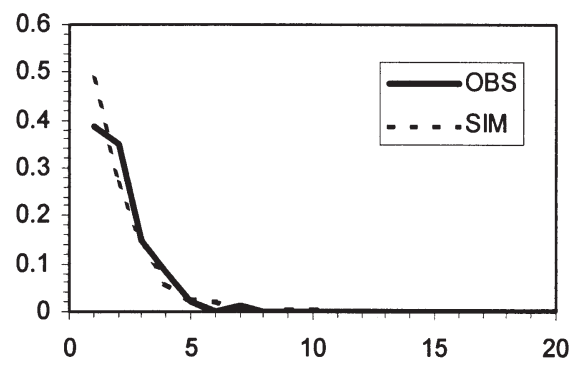

Dry spells in December at Ottawa

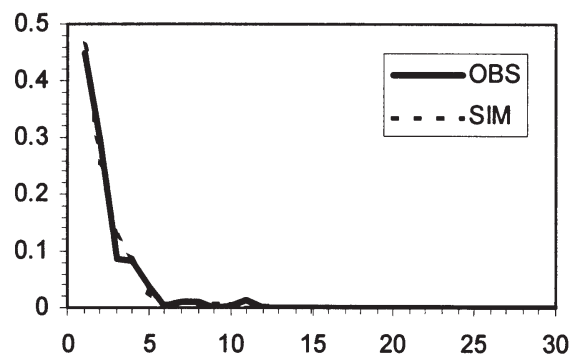

Wet spells in May at Toronto

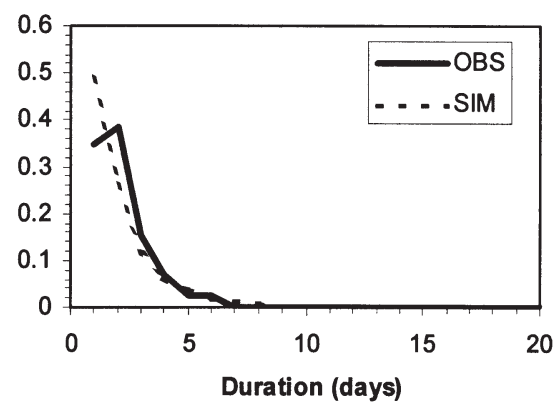

Fig. 4. Simulations of wet and dry spells by LARS-WG for 1971-2000, in comparison with observations

tions than the ones from LARS-WG for both Tx and Tn (Fig. 9). The simulations from AAFC-WG with application of different changes separately to wet and dry days were similar (not shown). It can be concluded that AAFC-WG can generate reliable future daily $\mathrm{Tx}$ and Tn scenarios based on climate change scenarios from monthly mean values of daily Tx and Tn and the corresponding SD of the daily values.

DTR is not modeled directly in the weather generators. Applying the same changes in mean temperatures to both Tx and Tn may fail to adequately simulate DTR in a changed climate, if DTR changes (as has been observed). Results from statistical tests for probability distribution, mean and variance of DTR are listed in Table 9. It appeared that both weather generators were deficient in reproducing the probability distribution of daily values of DTR. However, AAFC-WG reproduced the mean for both daily and monthly values of DTR, whereas LARS-WG did not. We analyzed synthetic temperature data generated by the 2 weather generators calibrated from observations of 1971-2000. Not surprisingly, both weather generators reproduced the mean of daily and monthly values of DTR, although failures in reproducing probability distribution and variance were often observed. This indicates that neither stochastic weather generator has the capability to reproduce the probability distributions of daily values of DTR and variance, but failure in reproducing the mean of daily and monthly values of DTR for a changed climate by LARS-WG was associated with its parameter adjustment for temperature. Applying the same changes in mean temperature may result in failure to reproduce the mean of daily and monthly values of DTR. 


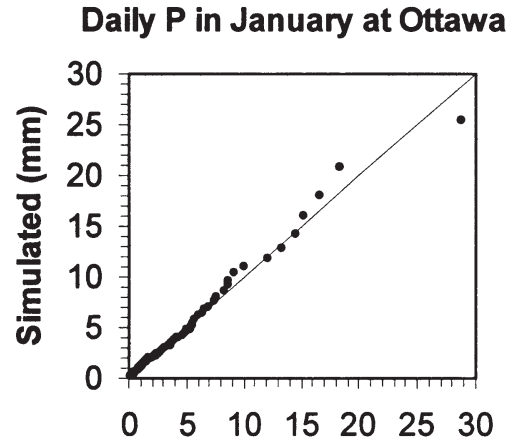

Daily $P$ in July at Regina

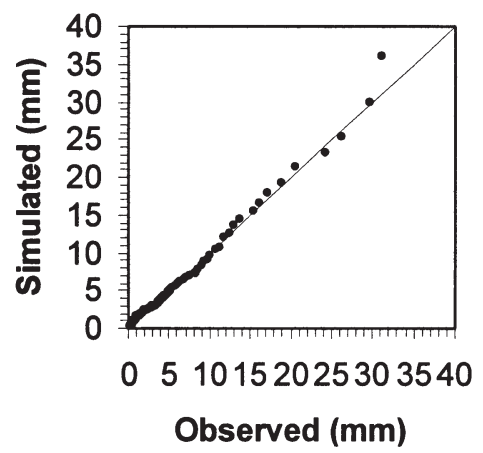

Daily $P$ in July at Ottawa

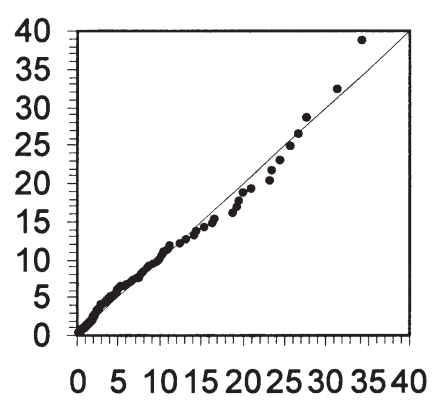

Daily $\mathbf{P}$ in January at Toronto

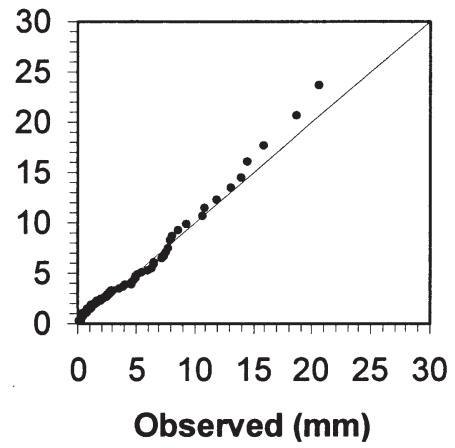

Daily $P$ in January at Regina

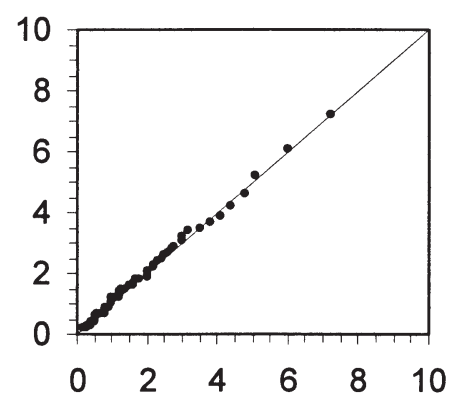

Daily $\mathbf{P}$ in July at Toronto

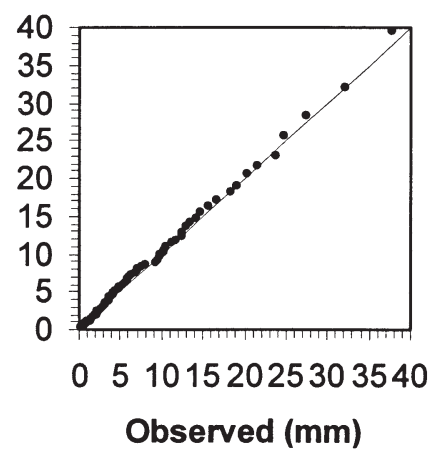

Fig. 5. Q-Q plots of daily precipitation amount (P) generated by AAFC-WG with mixed exponential distributions for 1971-2000, in comparison with observations

Daily $P$ in January at Ottawa

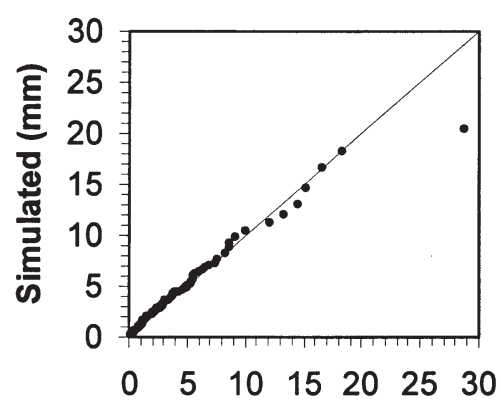

Daily $P$ in July at Regina

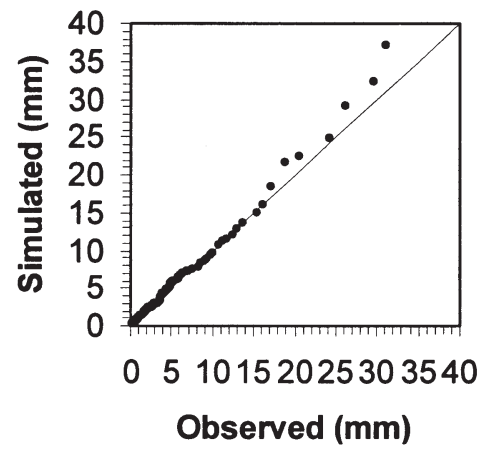

Daily $P$ in July at Ottawa

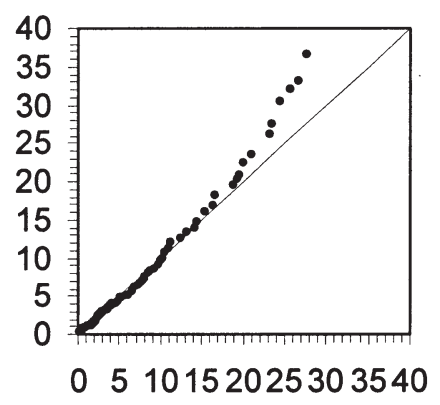

Daily $\mathbf{P}$ in January at Toronto

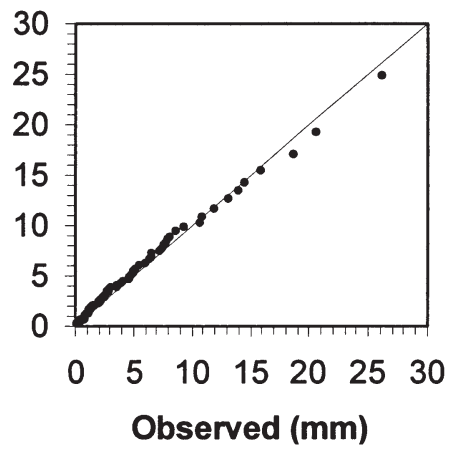

Daily $\mathbf{P}$ in January at Regina

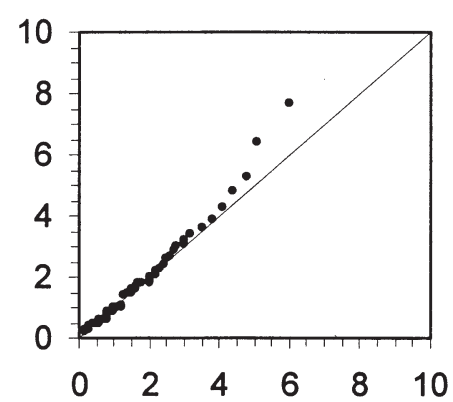

Daily $\mathbf{P}$ in July at Toronto

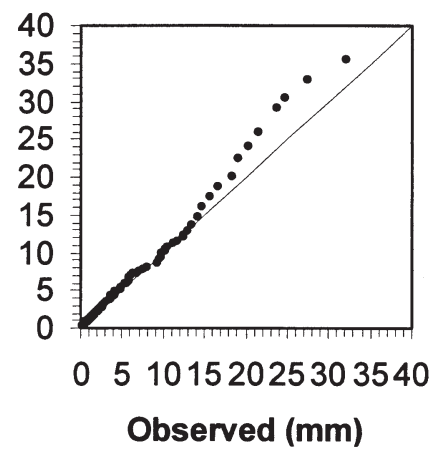

Fig. 6. Q-Q plots of daily precipitation amount (P) generated by AAFC-WG with empirical distributions for 1971-2000, in comparison with observations 


\subsection{Agroclimatic indices}

Producing reliable statistics for agroclimatic indices is important both for evaluating impacts of climate change and for developing corresponding adaptation strategies in the agricultural sector. It is essential that

Table 7. Number of months with significant differences between observed and simulated data with regard to distribution (D), mean (M) and variance (V) of daily and monthly maximum temperature (Tx) for 1971-2000. AAFC-WG tested with unconditional (AAFC-UNC) and with conditional (AAFC-CON) modification to mean and variance of daily Tx

\begin{tabular}{|lccccc|} 
& \multicolumn{3}{c}{ Daily } & \multicolumn{3}{c|}{ Monthly } \\
& $\mathrm{D}$ & $\mathrm{M}$ & $\mathrm{V}$ & $\mathrm{M}$ & $\mathrm{V}$ \\
\hline Ottawa & & & & & \\
LARS-WG & 5 & 3 & 3 & 2 & 2 \\
AAFC-UNC & 0 & 0 & 0 & 0 & 1 \\
AAFC-CON & 0 & 0 & 0 & 0 & 2 \\
Regina & & & & & \\
LARS-WG & 2 & 1 & 0 & 1 & 4 \\
AAFC-UNC & 0 & 0 & 0 & 0 & 5 \\
AAFC-CON & 0 & 0 & 0 & 0 & 5 \\
Toronto & & & & & \\
LARS-WG & 10 & 9 & 2 & 1 & 4 \\
AAFC-UNC & 0 & 0 & 0 & 0 & 1 \\
AAFC-CON & 0 & 0 & 0 & 0 & 1 \\
\hline
\end{tabular}

the mean values of the indices be reliable, since these can have implications for crop-growing conditions. AAFC-WG successfully simulated mean values of agroclimatic indices, except for Ottawa, where significant differences were found for several indices, and for Toronto, which had significant differences for precipi-
Table 8. Number of months with significant differences between observed and simulated data with regard to distribution (D), mean (M) and variance (V) of daily and monthly minimum temperature (Tn) for 1971-2000. AAFC-WG tested with unconditional (AAFC-UNC) and with conditional (AAFC-CON) modification to mean and variance of daily $\mathrm{Tn}$

\begin{tabular}{|lrrrrr|}
\hline & \multicolumn{3}{c}{ Daily } & \multicolumn{3}{c|}{ Monthly } \\
& $\mathrm{D}$ & $\mathrm{M}$ & $\mathrm{V}$ & $\mathrm{M}$ & $\mathrm{V}$ \\
\hline Ottawa & & & & & \\
LARS-WG & 10 & 9 & 4 & 8 & 1 \\
AAFC-UNC & 0 & 0 & 0 & 0 & 1 \\
AAFC-CON & 0 & 0 & 0 & 0 & 1 \\
Regina & & & & & \\
LARS-WG & 6 & 5 & 5 & 5 & 5 \\
AAFC-UNC & 0 & 0 & 0 & 0 & 4 \\
AAFC-CON & 0 & 0 & 0 & 0 & 3 \\
Toronto & & & & & \\
LARS-WG & 11 & 9 & 0 & 5 & 5 \\
AAFC-UNC & 0 & 0 & 0 & 0 & 1 \\
AAFC-CON & 0 & 0 & 0 & 0 & 1 \\
\hline
\end{tabular}

Daily $P$ in January at Ottawa

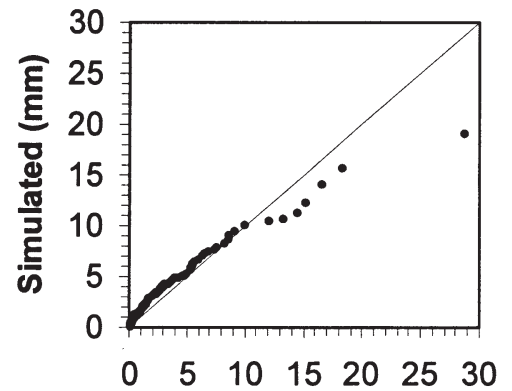

Daily $P$ in July at Regina

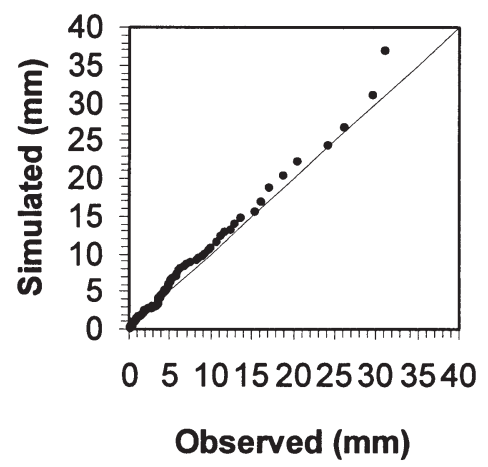

Daily $P$ in July at Ottawa

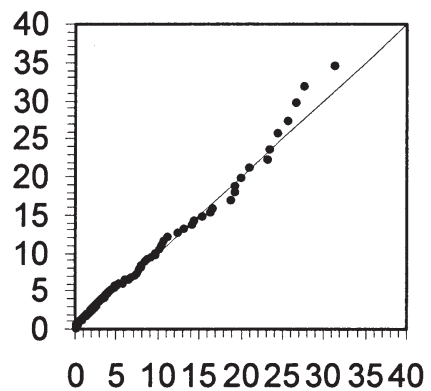

Daily $\mathbf{P}$ in January at Toronto

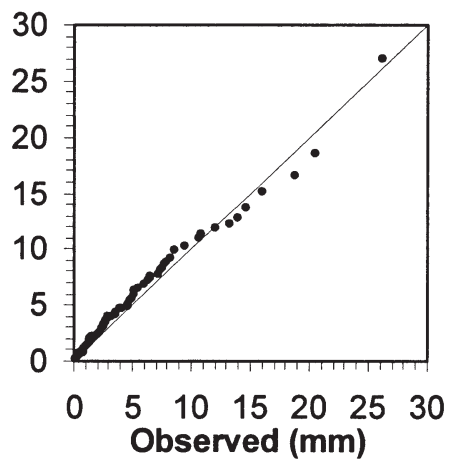

Daily $P$ in January at Regina

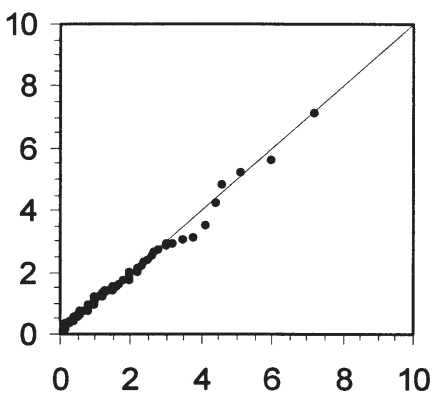

Daily $\mathbf{P}$ in July at Toronto

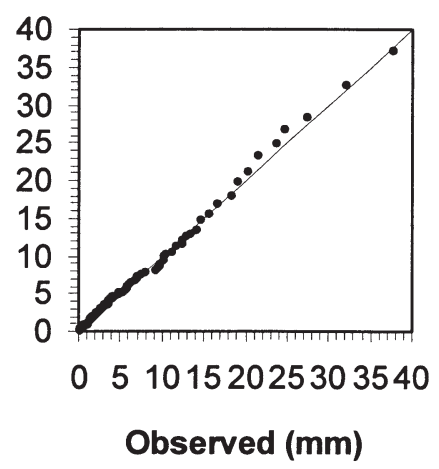

Fig. 7. Q-Q plots of daily precipitation amount (P) generated by LARS-WG for 1971-2000, in comparison with observations 
tation deficit (Table 10). Some skill should have been apparent, since some indices did not change significantly between the 2 periods. Failure to replicate the PDS was related to the simulations for precipitation, as some cases with significant differences to observations were for the months in the growing season. Simula- tions from LARS-WG were not as successful as AAFCWG (Table 10), where the last frost dates in spring were not reproduced successfully for any of the 3 sites. Furthermore, failures were found for frost-free days. Similar results were observed for the dates of killing frost. The deficiency in reproducing agroclimatic
Daily Tx in January at Ottawa

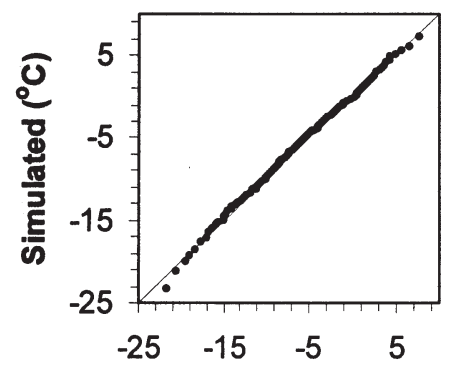

Daily $\mathrm{Tn}$ in July at Ottawa

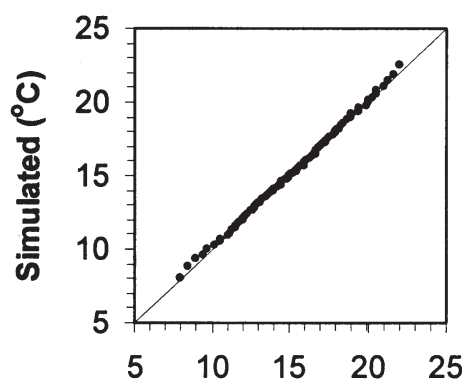

Daily Tx in July at Regina

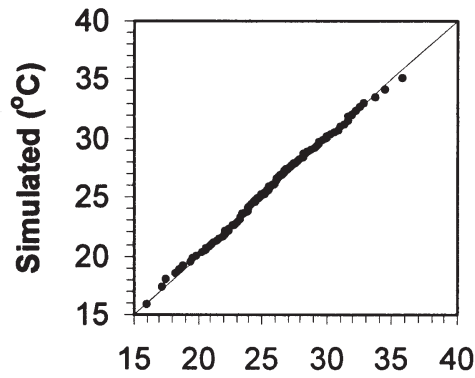

Daily $\mathrm{Tn}$ in January at Toronto

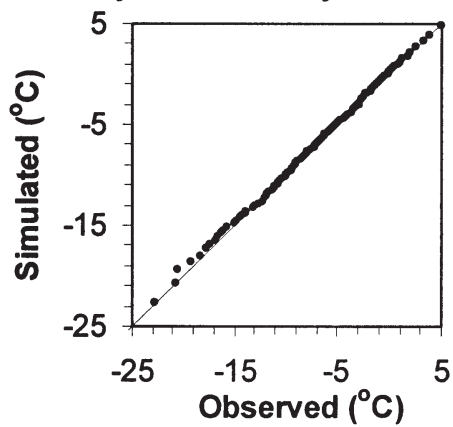

Daily $\mathrm{Tn}$ in January at Ottawa

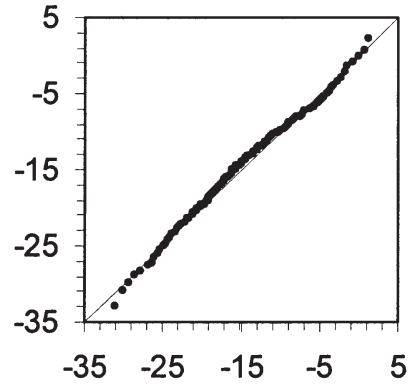

Daily Tx in January at Regina

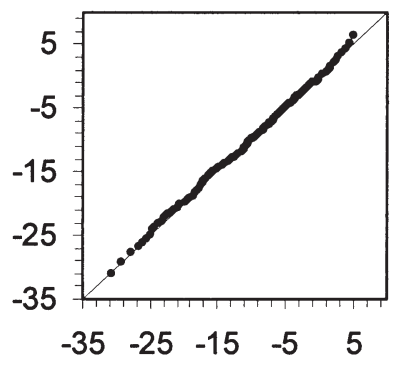

Daily $\mathrm{Tn}$ in July at Regina

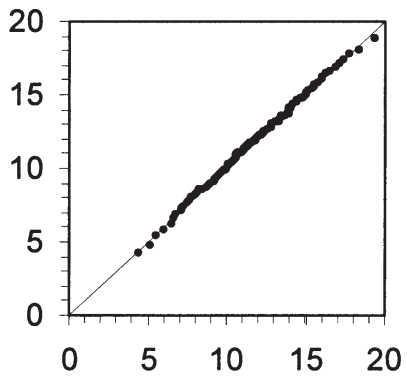

Daily $\mathrm{Tx}$ in July at Toronto

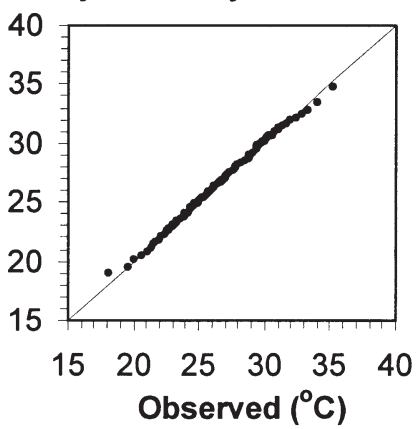

Daily Tx in July at Ottawa

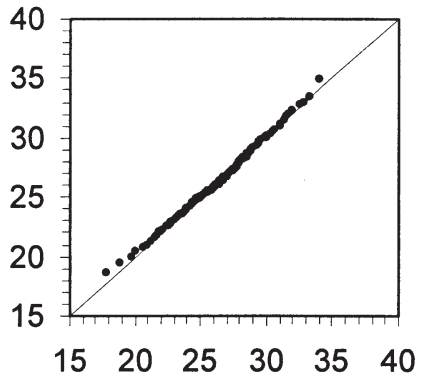

Daily $\mathrm{Tn}$ in January at Regina

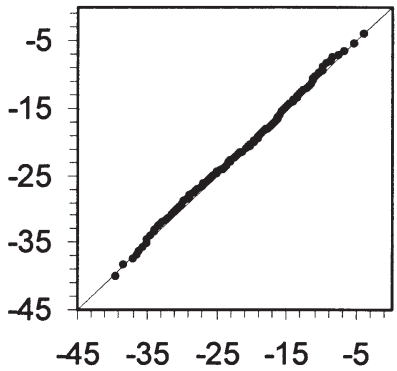

Daily Tx in January at Toronto

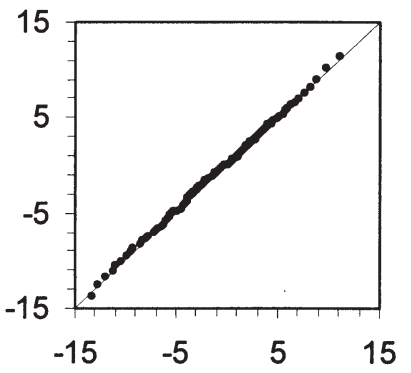

Daily $\mathrm{Tn}$ in July at Toronto

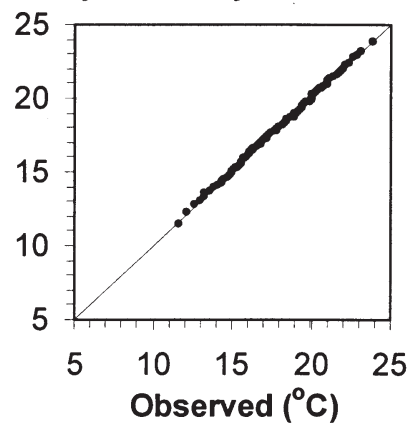

Fig. 8. Q-Q plots of daily maximum (Tx) and minimum (Tn) temperature generated by AAFC-WG for 1971-2000, in comparison with observations 
indices by LARS-WG might partly be a result of the assumption of normality in the probability distribution of daily Tx and Tn. This could also be associated with the method used in modifying temperature parameters for a changed climate.
It follows that AAFC-WG had the capability to simulate changes in the means of agroclimatic indices through modifications to the weather generator parameters based on changes in statistics of daily weather series.
Daily Tx in January at Ottawa

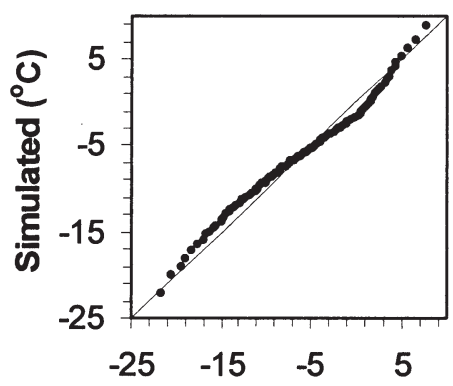

Daily Tn in July at Ottawa

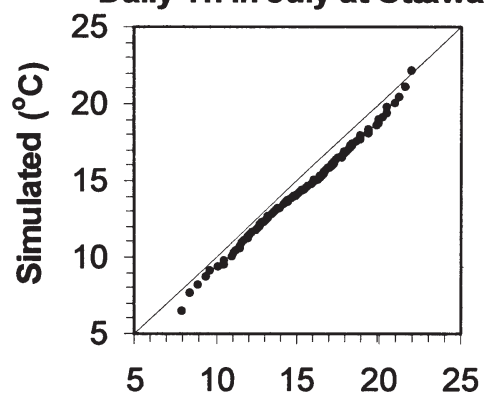

Daily Tx in July at Regina

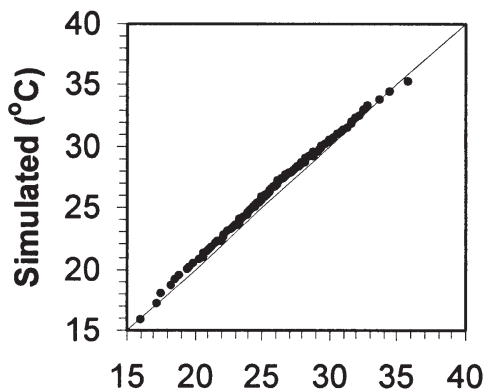

Daily $\mathrm{Tn}$ in January at Toronto

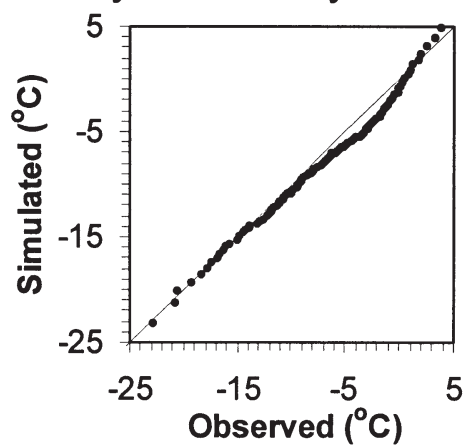

Daily Tn in January at Ottawa

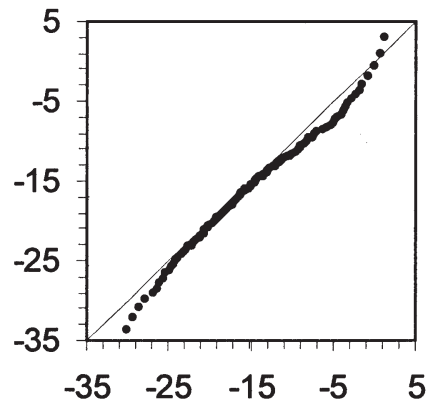

Daily Tx in January at Regina

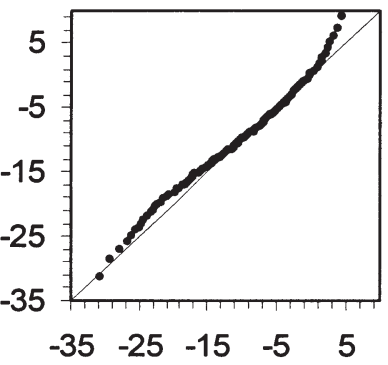

Daily Tn in July at Regina

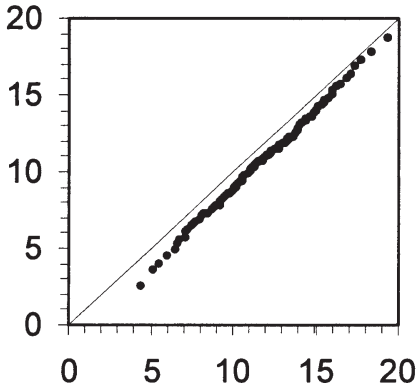

Daily Tx in July at Toronto

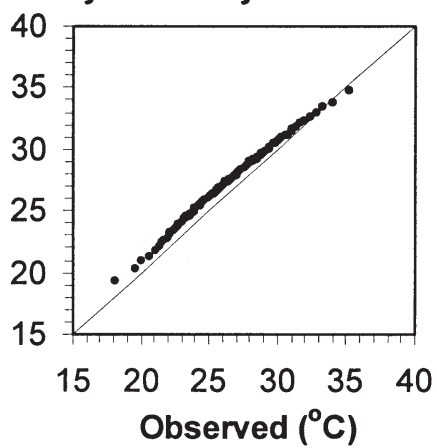

Daily Tx in July at Ottawa

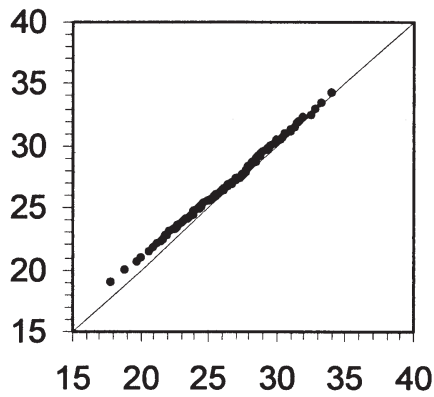

Daily $\mathrm{Tn}$ in January at Regina

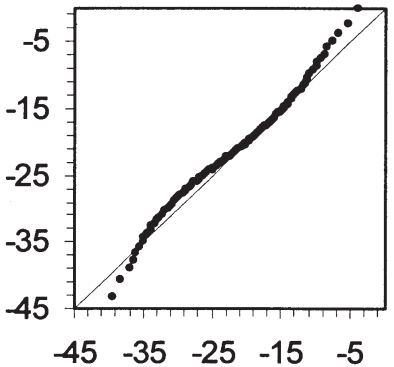

Daily Tx in January at Toronto

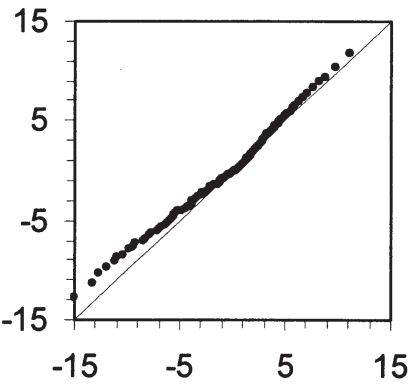

Daily $\mathrm{Tn}$ in July at Toronto

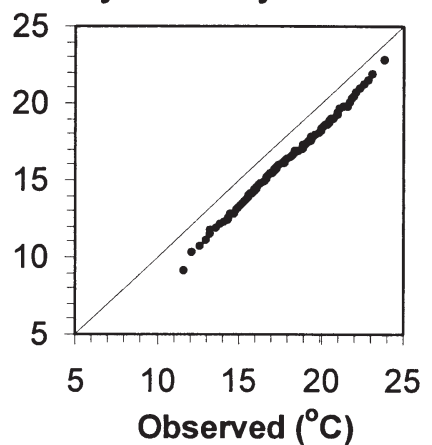

Fig. 9. Q-Q plots of daily maximum (Tx) and minimum (Tn) temperature generated by LARS-WG for 1971-2000, in comparison with observations 
Table 9. Number of months with significant differences between observed and simulated data with regard to distribution (D), mean (M) and variance (V) of daily temperature range (DTR) and monthly mean for 1971-2000. AAFC-WG tested with unconditional (AAFC-UNC) and with conditional (AAFC-CON) modification to mean and variance of daily Tx and Tn

\begin{tabular}{|lrrrrr|} 
& \multicolumn{3}{c}{ Daily } & \multicolumn{3}{c|}{ Monthly } \\
& $\mathrm{D}$ & $\mathrm{M}$ & $\mathrm{V}$ & $\mathrm{M}$ & $\mathrm{V}$ \\
\hline Ottawa & & & & & \\
LARS-WG & 11 & 11 & 9 & 11 & 10 \\
AAFC-UNC & 8 & 0 & 5 & 0 & 1 \\
AAFC-CON & 9 & 0 & 5 & 0 & 2 \\
Regina & & & & & \\
LARS-WG & 10 & 6 & 9 & 6 & 6 \\
AAFC-UNC & 8 & 0 & 11 & 0 & 5 \\
AAFC-CON & 6 & 0 & 8 & 0 & 6 \\
Toronto & & & & & \\
LARS-WG & 12 & 12 & 12 & 12 & 12 \\
AAFC-UNC & 11 & 0 & 9 & 0 & 3 \\
AAFC-CON & 11 & 0 & 9 & 0 & 3 \\
\hline
\end{tabular}

\section{CONCLUSIONS}

This study tested the abilities of weather generators that use empirical distributions for simulating a changed climate, with an emphasis on agricultural applications. Different modification schemes for weather generator parameters were applied for simulating a changed climate with a focus on agricultural applications. Daily climate change scenarios were characterized with differences (additive changes) and ratios (multiplicative changes) of the statistics of daily weather variables for 2 different time periods.

Using AAFC-WG, a full modification to the 4 transition probabilities for the second-order Markov chain model was able to reproduce wet and dry spells better than a partial modification scheme, where only changes in the first-order transition probabilities were applied. This method also gave better distributions of relative frequency of wet and dry spells than the LARS-WG approach using an empirical distribution for wet and dry spells, with modification of their mean length. Empirical distributions of wet and dry spells could become different in a changed climate, and modifying mean length of wet and dry spells might not reflect such changes. However, the second-order transition probabilities seemed capable of accommodating such changes.

The probability distribution of daily $\mathrm{P}$ appeared to be the most difficult to accurately simulate for a changed climate. Modifications were applied to both standard probability distributions (mixed exponential distribution) and empirical distributions, but no consistent advantage was found for either method. Nevertheless,
Table 10. Mean of agroclimatic indices computed from synthetic weather data generated for 1971-2000. * Significantly different from observed data; $\mathrm{p}<0.05$

\begin{tabular}{|lcc|}
\hline & LARS- & AAFC- \\
& WG & WG \\
\hline Ottawa & & \\
Last date of frost in spring (FS) & $128^{*}$ & $122^{*}$ \\
First date of frost in fall (FF) & 276 & 278 \\
Last date of killing frost in spring (KFS) & $118^{*}$ & $114^{*}$ \\
First date of killing frost in fall (KFF) & 287 & 289 \\
Frost free days (FFD) & $147^{*}$ & 155 \\
Growing degree-days (GDD) & 2047 & 2092 \\
Effective growing degree-days (EGDD) & 1923 & 1972 \\
Corn heat units (CHU) & 2882 & $2976^{*}$ \\
Precipitation deficit (mm) & $179^{*}$ & $76^{*}$ \\
Regina & & \\
Last date of frost in spring (FS) & $148^{*}$ & 141 \\
First date of frost in fall (FF) & 252 & 259 \\
Last date of killing frost in spring (KFS) & $137^{*}$ & 132 \\
First date of killing frost in fall (KFF) & $263^{*}$ & 266 \\
Frost free days (FFD) & $103^{*}$ & 116 \\
Growing degree-days (GDD) & 1652 & 1679 \\
Effective growing degree-days (EGDD) & $1458^{*}$ & 1535 \\
Corn heat units (CHU) & 2162 & 2195 \\
Precipitation deficit (mm) & 361 & 330 \\
Toronto & \multicolumn{2}{c}{} \\
Last date of frost in spring (FS) & $115^{*}$ & 109 \\
First date of frost in fall (FF) & $299^{*}$ & 307 \\
Last date of killing frost in spring (KFS) & $105^{*}$ & 100 \\
First date of killing frost in fall (KFF) & $310^{*}$ & 320 \\
Frost free days (FFD) & $182^{*}$ & 197 \\
Growing degree-days (GDD) & 2283 & 2409 \\
Effective growing degree-days (EGDD) & 2301 & 2359 \\
Corn heat units (CHU) & 3385 & 3506 \\
Precipitation deficit (mm) & $178^{*}$ & $44^{*}$ \\
& & \\
\hline
\end{tabular}

satisfactory simulations were achieved for a weak majority of months and locations. As empirical distributions were created from after log-transformation, modification to the stochastic precipitation model in AAFC-WG was only applied to the mean and SD of log-transformed daily P. The modification was straightforward and easy, since it involved changes in the statistics of daily $\mathrm{P}$, as in the method used to modify conventional gamma distributions through changes in the statistics of monthly precipitation totals.

Modifications for temperature modeling were simple as well. Empirical distributions and correlation matrices of their standardized daily values were the same for the first-order multivariate autoregressive models. Changes in mean and SD were applied to modify the annual cycles. As temperature is conditional on precipitation occurrence, modifications to the annual cycles were made separately for wet and dry days, or the same changes were applied for both wet and dry days. There were no remarkable advantages in simulations with conditional changes, and the 
changes projected by GCMs may not be very reliable, because GCMs usually produce too many wet days and may provide unreliable means and SD for temperature on wet days. However, the lack of an advantage in simulations with conditional changes relative to unconditional changes might be related to the constraint in AAFC-WG to preserve the mean and variance in temperature scenarios to which bias might be introduced by precipitation occurrence models. Adjusting the mean and variance of daily temperature on wet days and dry days was performed in AAFC-WG in accordance with the number of wet days generated by precipitation occurrence models, in order to preserve the mean and variance introduced for a changed climate. Simulations indicated that AAFCWG could generate realistic daily temperature scenarios, evaluated on statistical properties such as probability distribution, mean and variance, for a changed climate. It was also clear that applying different changes in $\mathrm{Tx}$ and $\mathrm{Tn}$ seemed necessary rather than using the same changes in mean temperatures for both Tx and Tn.

Stochastic weather generators were not able to reproduce DTR well, even if they could accurately reproduce both daily Tx and Tn. To solve this problem, introducing daily temperature range as a variable in weather generators may be necessary to preserve the statistical properties of DTR. For example, 2 variables conventionally simulated in weather generators, daily Tx and $T n$, could be replaced by daily Tx and DTR.

Changes in mean values of agroclimatic indices were produced reasonably by AAFC-WG through generating daily climate scenarios for a changed climate, although failure was found in a few cases. This gives confidence that changes in mean values of agroclimatic indices can be used to investigate potential impacts on agricultural production when the scenarios of agroclimatic indices are obtained from daily climate scenarios generated by AAFC-WG.

The performance of the weather generators in simulating climate change was assessed using observed changes in 2 different periods. The details of a changed climate were accurately observed and thus changes in the statistics of daily weather variables could be computed exactly. However, it is not guaranteed that GCMs are reliable in producing such details, although it is reasonable to believe that changes in the statistics of daily weather variables simulated by GCMs may be more reliable than the actual values of daily weather variables and the corresponding statistics (Carter et al. 1994). Nevertheless, other downscaling techniques may be applied to obtain changes in the statistics of daily weather variables as inputs to weather generators if the changes estimated from daily weather variables directly from
GCM output are not considered reliable (this is beyond the scope of this study). On the other hand, conditional weather generators (e.g. Corte-Real et al. 1999) can be used, rather than unconditional weather generators (e.g. LARS-WG and AAFC-WG), to address concerns about the reliability of changes in the statistics of daily weather variables taken directly from GCM outputs.

Acknowledgements. We acknowledge the support of the Government of Canada's Climate Change Action Fund. We are grateful to M. A. Semenov and E. M. Barrow for making the software LARS-WG Stochastic Weather Generator 3.0 available. Internal reviews by R. De Jong and S. McGinn provided many helpful comments for improving the manuscript. We thank anonymous reviewers for critical comments, which helped to improve the manuscript. This is ECORC Contribution No. 04-435.

\section{LITERATURE CITED}

Carter TR, Parry ML, Harasawa H, Nishioka S (1994) IPCC technical guidelines for assessing climate change impacts and adaptations. University College London, UK, and Center for Global Environmental Research, Tsukuba, Japan, p 52-53

Corte-Real J, Xu H, Qian B (1999) A weather generator for obtaining daily precipitation scenarios based on circulation patterns. Clim Res 13:61-75

Folland CK, Karl TR, Christy JR, Clarke RA and 6 others (2001) Observed climate variability and change. In: Houghton JT, Ding Y, Griggs DJ, Noguer M, van der Linden PJ, Dai X, Maskell K, Johnson CA (eds) Climate change 2001: the scientific basis. Contribution of Working Group I to the Third Assessment Report of the Intergovernmental Panel on Climate Change. Cambridge University Press, Cambridge, p 99-181

Hayhoe HN (2000) Improvements of stochastic weather data generators for diverse climates. Clim Res 14:75-87

Jones PD, Osborn TJ, Briffa KR (2001) The evolution of climate over the last millennium. Science 292:662-667

Katz RW (1983) Statistical procedures of making inferences about precipitation changes simulated by an atmospheric general circulation model. J Atmos Sci 40:2193-2201

Katz RW (1985) Probabilistic models. In: Murphy AH, Katz RW (eds) Probability, statistics, and decision making in the atmospheric sciences. Westview Press, Boulder, CO, p 261-288

Katz RW (1996) The use of stochastic models to generate climate scenarios. Clim Change 32:237-255

Mearns LO, Bogardi I, Giorgi F, Matyasovszky I, Palecki M (1999) Comparison of climate change scenarios generated from regional climate model experiments and statistical downscaling. J Geophys Res 104:6603-6622

Mearns LO, Rosenzweig C, Goldberg R (1997) Mean and variance change in climate scenarios: methods, agricultural applications, and measures of uncertainty. Clim Change 35:367-396

Qian B, Gameda S, Hayhoe H, De Jong R, Bootsma A (2004a) Comparison of LARS-WG and AAFC-WG stochastic weather generators for diverse Canadian climates. Clim Res 26:175-191 
Qian B, Gameda S, Hayhoe H, De Jong R, Bootsma A (2004b) Resampling tests - a possible alternative to the standard statistical tests with caution: Reply to Semenov \& Welham (2004). Clim Res 28:85-87

Richardson CW (1981) Stochastic simulation of daily precipitation, temperature, and solar radiation. Water Res 17:182-190

Semenov MA, Barrow EM (1997) Use of a stochastic weather generator in the development of climate change scenarios. Clim Change 35:397-414

Semenov MA, Barrow EM (2002) LARS-WG: a stochastic weather generator for use in climate impact studies (Version 3.0). User Manual. Available at: www.rothamsted. bbsrc.ac.uk/mas-models/larswg.html

Editorial responsibility: Otto Kinne,

Oldendorf/Luhe, Germany
Semenov MA, Brooks RJ, Barrow EM, Richardson CW(1998) Comparison of the WGEN and LARS-WG stochastic weather generators for diverse climates. Clim Res 10:95-107

Wilby RL, Wigley TML (2002) Future changes in the distribution of daily precipitation totals across North America. Geophys Res Lett 29, 1135, doi:10.1029/2001GL013048

Wilks DS (1992) Adapting stochastic weather generation algorithms for climate change studies. Clim Change 22:67-84

Wilks DS (1995) Statistical methods in the atmospheric sciences. Academic Press, San Diego, CA

Wilks DS (1999) Interannual variability and extreme-value characteristics of several stochastic daily precipitation models. Agric For Meteorol 93:153-169

Submitted: September 2, 2004; Accepted: May 3, 2005

Proofs received from author(s): June 16, 2005 